\title{
Uma Implementação do Protocolo TLS com um Algoritmo de Criptografia Forte
}

\author{
Isvi Corrêa Júnior
}

DissertaÇÃo Apresentada ao Instituto DE MATEMÁTICA E EstatísticA DA UNIVERSIDADE DE SÃo PAULO COMO PARTE DOS REQUiSITOS PARA A OBTENÇÃo DO GRAU DE Mestre em CiÊnCia da Computação

Área de Concentração: Criptografia Orientador: Prof. Dr. Routo Terada

São Paulo - Maio de 2002 


\section{Uma Implementação \\ do Protocolo TLS \\ com um Algoritmo de \\ Criptografia Forte}

Este exemplar corresponde à redação final da dissertação devidamente corrigida

e defendida por Isvi Corrêa Júnior

e aprovada pela comissão julgadora.

São Paulo, 17 de maio de 2002.

Banca examinadora:

- Prof. Dr. Routo Terada (orientador) - IME - USP

- Prof. Dr. Jaime Simão Sichman - Escola Politécnica da USP

- Prof. Dr. Marco Dimas Gubitoso - IME - USP 


\section{Agradecimentos}

- Ao Professor Routo Terada pela ótima orientação.

- Aos Professores Jaime Simão Sichman e Marco Dimas Gubitoso, pela participação na banca examinadora e pelas sugestões apontadas após a exposição da dissertação.

- Aos amigos e companheiros de trabalho Helves Humberto Domingues e Wellington Brigante, pelo apoio e incentivo.

- À minha querida esposa Eunice, pelo carinho, estímulo, paciência, compreensão e incentivo em todos os momentos, principalmente os difíceis.

- Aos meus filhos Jorge, Carolina e Caio, pelo carinho e paciência com seu pai nos momentos difíceis.

- Aos meus pais, Cida e Isvi que sempre apoiaram meus estudos.

- Aos meus irmãos Zizi, Marcelo e Bianca pelo apoio e dicas. 


\section{Resumo}

Esta dissertação propõe uma implementação do Protocolo TLS 1.0, cujo principal objetivo é o aumento da segurança na comunicação entre aplicações. Na implementação utilizamos a linguagem Java e os serviços do protocolo de transporte TCP. Isto possibilita sua utilização em grande variedade de aplicações.

Para o projeto desta implementação, o protocolo TLS 1.0 foi analisado sob dois aspectos. $\mathrm{O}$ primeiro quanto a sua capacidade de resistir a manipulações por alguém que se coloque no meio de comunicação. O segundo quanto a segurança dos algoritmos básicos propostos na especificação TLS 1.0. Com base nesta análise fizemos duas alterações. A primeira foi a inclusão, no conjunto de algoritmos do TLS, do algoritmo de criptografia em blocos RC6 com uma alteração para fortalecê-lo contra criptanálise diferencial. A outra alteração foi na verificação das chaves no sub-protocolo para troca de chaves. 


\begin{abstract}
This dissertation proposes an implementation of the TLS 1.0 Protocol, which aims mainly at increasing the security among communicating applications. In the implementation we used the Java language and services of the transport protocol TCP. This enables its use by a large range of applications.

In the design of this implementation, the TLS protocol was analyzed twofold. First, the TLS resistance against an active attacker in the middle of the communication channel. Second, the security of the basic cryptographic algorithms proposed in the TLS specification. Based on this analysis we did two improvements. The first, we included a modified version of the RC6 block cipher in the cipher suite, so that RC6 is stronger against differential cryptanalysis. The second one was an improvement in the verification of the keys in the key exchange protocol.
\end{abstract}




\section{Sumário}

1 Introdução 5

1.1 Conceitos básicos . . . . . . . . . . . . . . . . . 7

1.1.1 Algoritmo criptográfico em blocos iterado . . . . . . . . . . . 7

1.1.2 Ataques a algoritmos criptográficos . . . . . . . . . . . . . . 7

1.1.3 Segurança computacional . . . . . . . . . . . . . . . 8

1.1.4 Criptanálise Diferencial . . . . . . . . . . . . . . . . . . . 9

1.2 Organização da dissertação $\ldots \ldots \ldots \ldots \ldots \ldots$

2 Trabalhos relacionados $\quad 11$

3 Protocolo Transport Layer Security , TLS $1.0 \quad 12$

3.1 Arquitetura . . . . . . . . . . . . . . . . . . . . 12

3.2 A camada TLS Record . . . . . . . . . . . . . . . . . . . 15

3.2 .1 Estados da conexão . . . . . . . . . . . . . . . . . . . 16

3.3 Protocolo TLS Handshake . . . . . . . . . . . . . . . . . . . . . . 18

3.3.1 Protocolo Change Cipher Spec . . . . . . . . . . . . . . . . . . 18

3.3 .2 Protocolo Alert . . . . . . . . . . . . . . . . . . . . . . . . 18

3.3 .3 Protocolo Handshake . . . . . . . . . . . . . . . . . . . . . . . . . . . . . . . . . . . . . . .

3.4 Geração do Material Secreto . . . . . . . . . . . . . . . . . . . . . . . . . . . . . . . . . . . .

3.4.1 HMAC e a Função pseudo-aleatória . . . . . . . . . . . . . . 29

3.4 .2 Cálculo do Master Secret . . . . . . . . . . . . . . . . . . . 30

3.4 .3 Cálculo das chaves . . . . . . . . . . . . . . . . . . . . 31

4 Análise do Protocolo TLS 1.0 33

4.1 Camada TLS Record . . . . . . . . . . . . . . . . . . . . . . . . . . . . . . . . . . . . . .

4.1 .1 Privacidade . . . . . . . . . . . . . . . . . . . . . . . 33

4.1 .2 Autenticação de Mensagens. . . . . . . . . . . . . . . . . . . . . . . . . . . 34

4.1 .3 Ataque por Repetição de mensagens . . . . . . . . . . . . . . . . . . . . . . 34

4.2 Protocolo TLS Handshake . . . . . . . . . . . . . . . . . . . . . . . . . 34

4.2.1 Ataque por enfraquecimento do Cipher Suite . . . . . . . . . . . 34

4.2.2 Algoritmos diferentes para troca de chaves . . . . . . . . . . . . . 34

4.2 .3 Diffie-Hellman anônimo . . . . . . . . . . . . . . . . 35 
5 Protocolo para Troca de Chaves Diffie-Hellman 36

5.1 Problema do Algoritmo Discreto . . . . . . . . . . . . . . . . . . . 36

5.2 Diffie-Hellman . . . . . . . . . . . . . . . . . . . . . . 36

5.2.1 Ataque ativo do tipo "man-in-the-middle" . . . . . . . . . . . 36

5.2.2 Protocolo Diffie-Hellman modificado ... . . . . . . . . . . 37

6 Algoritmo de Criptografia em Blocos RC6 39

6.1 Parâmetros . . . . . . . . . . . . . . . . . . . . . . 39

6.2 Operações Básicas . . . . . . . . . . . . . . . . . . . . . . . . . . . . 39

6.3 Geração de Subchaves . . . . . . . . . . . . . . . . . . . . . . . . . 40

6.4 Criptografia e Decriptografia . . . . . . . . . . . . . . . . . . 41

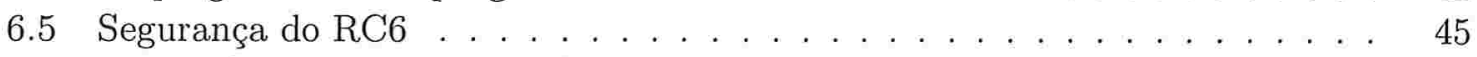

6.5 .1 Ataques contra o RC6 . . . . . . . . . . . . . . 45

7 Criptanálise Diferencial do RC6 46

7.1 Criptanálise diferencial do RC5 . . . . . . . . . . . . . . . . . . 46

7.2 A Função quadrática . . . . . . . . . . . . . . . . . . . . . . . . . . . . . . . . . . .

7.2 .1 Propriedades básicas . . . . . . . . . . . . . . . 47

7.3 Subtração de inteiros como medida de diferença . . . . . . . . . . . . . . . 47

7.4 Ou-exclusivo como medida de diferença . . . . . . . . . . . . . . . . . 48

7.5 Comparando subtração de inteiros e ou-exclusivo . . . . . . . . . . . . . 48

7.6 Características e Diferenciais Iterativos para o RC6 . . . . . . . . . . . . . 49

7.7 Diferenciais não iterativos para o RC6 . . . . . . . . . . . . . . . . 50

8 Algoritmo RC6 modificado $\quad \mathbf{5 4}$

8.1 RC6T: O RC6 com trocas . . . . . . . . . . . . . . . . . . . . 54

8.2 Propriedades da função de troca $T \ldots \ldots \ldots \ldots$. . . . . . . . 60

9 Análise do Algoritmo RC6 modificado $\quad 64$

9.1 Características e Diferenciais Iterativos para o RC6T . . . . . . . . . . . 64

10 Implementação $\quad 66$

10.1 Ambiente de desenvolvimento . . . . . . . . . . . . . . . 66

10.2 Algoritmo RC6 modificado . . . . . . . . . . . . . . . 66

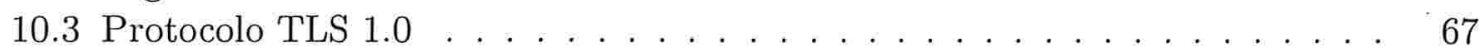

10.3 .1 Alterações . . . . . . . . . . . . . . . . . . . . . . . . . . . . . . . . . . . . . .

10.3 .2 Utilização . . . . . . . . . . . . . . . . . . . . . . . . . . 68

10.4 Aplicação distribuída para testes . . . . . . . . . . . . . . . 71

11 Conclusão $\quad 73$

11.1 Trabalhos futuros . . . . . . . . . . . . . . . . . . . 73

$\begin{array}{ll}\text { A Glossário } & 74\end{array}$ 


\section{Lista de Figuras}

3.1 Arquitetura do TLS . . . . . . . . . . . . . . . . . . . . . . . . 14

3.2 Camada TLS Record . . . . . . . . . . . . . . . . . . . . . . . 16

3.3 Fluxo de mensagens para um handshake completo. A mensagem ChangeCipherSpec entre colchetes é um protocolo independente, e as mensagens com asterisco são opcionais. . . . . . . . . . . . . . . . . . . . . . . 23

3.4 Fluxo de mensagens para um handshake abreviado. . . . . . . . . . . . . . . . 24

3.5 Geração do material secreto compartilhado . . . . . . . . . . . . . . . . . . 29

3.6 Função de expansão . . . . . . . . . . . . . . . . . . . . . . . . 30

3.7 Geração do material secreto . . . . . . . . . . . . . . . . . . . . . 32

3.8 Geração das chaves finais e vetores de iniciação para algoritmos exportáveis 32

4.1 Resumo do ataque por algoritmos diferentes para troca de chaves . . . . . . 35

5.1 Protocolo para Combinação de Chave Secreta Diffie-Hellman . . . . . . . . 37

6.1 Geração de subchaves do RC6-w/r/b . . . . . . . . . . . . . . . . . 40

6.2 Algoritmo de criptografia RC6-w/r/b . . . . . . . . . . . . . . . 41

6.3 Criptografia com o RC6 $-w / r / b$. Onde $f(x)=x(2 x+1) \ldots \ldots \ldots . . . .42$

6.4 Algoritmo de decriptografia RC6- $w / r / b \ldots \ldots \ldots \ldots \ldots$

6.5 Decriptografia com o RC6 $-w / r / b$. Onde $f(x)=x(2 x+1) \ldots \ldots . \ldots 4$

8.1 Algoritmo de criptografia RC6T- $w / r / b \ldots \ldots \ldots \ldots$

8.2 Criptografia com o RC6T-w/r/b. Onde $f(x)=x(2 x+1)$ e $T$ função de troca 57

8.3 Algoritmo de decriptografia RC6T- $w / r / b \ldots \ldots \ldots \ldots$

8.4 Decriptografia com o RC6T-w/r/b. Onde $f(x)=x(2 x+1)$ e $T$ função de troca . . . . . . . . . . . . . . . . . . . 59

10.1 Exemplos de utilização das Classes do TLS $1.0 \ldots \ldots$. . . . . . . . . . . 70

10.2 Resultados dos testes com o RC6, RC6T com 20 iterações e RC6T com 12 iterações. Mensagens de $32 \mathrm{~Kb}$ e tempos em milisegundos. 


\section{Lista de Tabelas}

3.1 Métodos de troca de chaves e tipo de chaves contidas nos certificados . . . . 26

6.1 Estimativa de textos legíveis para atacar o RC6 [3] . . . . . . . . . . . . 45

7.1 Probabilidades para características estáticas para a função quadrática. [3] . 48

7.2 Característica iterativa genérica de seis iterações para o RC6 [3] . . . . . . . 50

7.3 Característica não iterativa genérica de seis iterações para o RC6 [3]. . . . . 51

7.4 Característica não iterativa genérica de duas, quatro e seis iterações para o RC6.Entre parênteses estão as probabilidades associadas aos diferencias[3]. . 52

7.5 Estimativa de textos legíveis para atacar o RC6 [3] . . . . . . . . . . . . 53

9.1 Estimativa de textos legíveis para atacar o RC6T [3] . . . . . . . . . 65

10.1 Alterações na implementação do protocolo TLS $1.0 \ldots \ldots$. . . . . . . . . . 69 


\section{Capítulo 1}

\section{Introdução}

A proteção às informações sigilosas tem sido uma preocupação antiga da humanidade, através dos séculos foram elaborados diversos protocolos e mecanismos para garantir a privacidade na comunicação de informações sigilosas. Com o surgimento dos computadores e sistemas de comunicação, surgiu a necessidade de proteção da informação em sua forma digital.

Nos dias atuais, com o crescimento explosivo da rede Internet e de redes com cobertura regional existem diversas aplicações distribuídas que trocam dados sigilosos entre os nós destas redes, como por exemplo, home banking e comércio eletrônico. Os principais objetivos de segurança neste cenário são os seguintes: privacidade da comunicação, integridade dos dados, autenticação das entidades envolvidas na comunicação e autenticação da origem dos dados.

Protocolos criptográficos são algoritmos distribuídos definidos por uma seqüência precisa de passos especificando as ações requeridas para duas ou mais entidades atingirem um objetivo de segurança específico [10]. Estes algoritmos distribuídos são construídos com várias primitivas criptográficas tais como funções de criptografia em bloco com chave simétrica, funções criptográficas de chave pública e privada, assinatura digital, funções de hash, funções de geração de números aleatórios entre outras. Estas funções podem estar combinadas em sub-protocolos, por exemplo, um sub-protocolo para combinação de chaves simétricas. Falhas em um protocolo podem ocorrer quando as primitivas criptográficas são fracas ou quando se é possível manipulá-lo para obter alguma vantagem.

O protocolo TLS 1.0 [5] busca atingir os objetivos de segurança necessários às aplicações distribuídas em redes não seguras como as citadas acima. Ele foi especificado de modo que seja independente da aplicação, que possa ser estendido facilmente e que seja também implementado de maneira eficiente.

O protocolo TLS 1.0 foi especificado a partir do protocolo SSL 3.0, que é hoje um padrão de facto para comunicação segura através da rede Internet, especialmente nos aplicativos para navegação que utilizam o protocolo HTTP. Ele foi proposto pelo grupo de trabalho Transport layer Security da organização Internet Engineering Task Force(IETF). Este grupo foi criado em 1996 e publicou como proposta de padrão em 1999 a especificação TLS 1.0 $[5]$.

Uma característica fundamental do protocolo TLS 1.0 é sua capacidade de ser estendido pela adição de novos conjuntos de algoritmos criptográficos. O protocolo TLS 1.0 utiliza 
para proteção dos dados da aplicação, algoritmos de chave simétrica, que são eficientes para encriptação de grandes quantidades de dados. Muitos dos algoritmos de chave simétrica disponíveis na especificação não são mais seguros e estão sendo quebrados, por máquinas cada vez mais poderosas e algoritmos distribuídos em um espaço de tempo cada vez menor. Nestas condições seria interessante utilizar um novo algoritmo de encriptação por chave simétrica que resistisse a ataques por um longo período.

Até hoje não se conhece um método matemático formal para se provar que um algoritmo criptográfico é seguro. A maneira mais próxima deste ideal que se conhece é publicá-lo e tê-lo analisado pelos pesquisadores especializados que conheçam os métodos mais sofisticados para atacá-lo. Se o algoritmo passa por tal escrutínio, a indústria aceita-o como seguro em relação ao estado da arte [17]. Baseado neste princípio o instituto americano de padronização, National Institute of Standards and Technology (NIST), abriu uma competição internacional em 1997 chamada AES - Advanced Encryption Standard -que tem por objetivo selecionar um algoritmo para substituir o DES - Data Encryption Standard - até o ano 2000. Os critérios para inscrição dos algoritmos eram os seguintes: que fossem públicos, disponíveis sem cobrança de royalties, implementassem criptografia por chave simétrica em blocos de 128 bits e com chaves de 128, 192 e 256 bits. Em abril de 1999 foram selecionados cinco candidatos após meses de análise por pesquisadores do mundo inteiro. Em 15 de Maio de 2000 foi encerrada a fase de comentários dos cinco algoritmos escolhidos e o NIST publicou um relatório de desempenho dos algoritmos implementados em hardware. Maiores detalhes em [11]

O primeiro passo para fortalecimento do TLS 1.0 seria pela adição de um novo algoritmo de encriptação de chave simétrica. Escolhemos o RC6 [12], um dos cinco finalistas da competição AES. O RC6 tem uma estrutura compacta, é uma cifra de Feistel, e é o que tem o melhor desempenho na implementação em Java [15], e o ambiente Java foi o escolhido para a implementação do protocolo TLS para este trabalho. O RC6 também foi alterado para melhorar sua resistência contra ataques por criptanálise diferencial. Quando decidimos pelo RC6 ele era um dos finalistas do AES, mas o algoritmo escolhido pelo AES em outubro de 2000 foi o Rijndael [4]. Atualmente, o RC6 participa do projeto europeu New European Schemes for Signatures, Integrity, and Encryption(NESSIE). O NESSIE tem objetivo mais amplo que o $A E S$, pois estará validando varias primitivas criptográficas.

A linguagem de programação Java tem se tornado popular nos últimos anos. O motivo principal é a sua independência de plataforma, e apesar de ter um desempenho abaixo de outras linguagens, como a linguagem " $\mathrm{C}$ ", vem sendo cada vez mais utilizada em aplicações distribuídas.

Neste trabalho tivemos como objetivo projetar e implementar um protocolo criptográfico, que atenda aos objetivos de segurança atuais, através da análise da especificação do protocolo TLS 1.0 e pela utilização de um algoritmo fortalecido contra criptanálise diferencial. A implementação é independente de plataforma e pode ser utilizada por qualquer aplicação distribuída que necessite de sigilo e possa utilizar os serviços de TCP/IP. Além do projeto e implementação também foi feito um estudo de "características" da função de troca proposta em [13] utilizando-se como "medida de diferença" a subtração de inteiros. 


\subsection{Conceitos básicos}

O objetivo fundamental da criptografia é permitir que duas pessoas se comuniquem através de um canal de comunicação inseguro, de modo que uma pessoa mal-intencionada não consiga entender o que está sendo dito. A informação que será transmitida é chamada de "texto legível". O texto legível é criptografado, utilizando-se uma chave predeterminada, e o "texto ilegível" é transmitido através do canal de comunicação. Uma pessoa mal-intencionada que tenha acesso ao canal de comunicação irá ver o texto ilegível e não conseguirá determinar o texto legível, mas a pessoa que recebe o texto e conhece a chave utilizada na criptografia poderá reconstruir o texto legível.[16]

Um algoritmo criptográfico ou função criptográfica é um método de escrita pelo qual um texto legível é transformado em texto ilegível. Esse processo de transformação é conhecido como criptografia e o processo reverso é chamado de decriptografia. Ambos os processos são controlados por uma ou mais chaves criptográficas. Dizemos que um algoritmo criptográfico é simétrico se a chave do processo de criptografia é a mesma utilizada no processo de decriptografia. Algoritmos criptográficos que processam blocos de tamanho fixo do texto legível são chamados de algoritmos de criptografia em blocos.

\subsubsection{Algoritmo criptográfico em blocos iterado}

Este tipo de algoritmo criptografa um bloco de texto legível pelo processamento de diversas iterações ou rounds. Em cada iteração, a mesma transformação (também conhecida como função de round) é aplicada aos dados utilizando uma subchave. O conjunto de subchaves geralmente é derivado de uma chave secreta fornecida pelo usuário e é gerado por uma função geradora de subchaves. O número de iterações depende de um balanço entre o nível de segurança desejada e o desempenho do algoritmo. Na maioria dos casos, um aumento do número de iterações irá melhorar a segurança oferecida pelo algoritmo, mas para alguns, este aumento pode torná-los não práticos para uso. Cifras de Feistel é uma classe especial de algoritmos criptográficos em blocos iterado, onde a cada iteração, sub-blocos do bloco de dados que esta sendo criptografados são permutados antes de serem passados para próxima iteração. As cifras de Feistel também são conhecidas como DES-like ciphers.

\subsubsection{Ataques a algoritmos criptográficos}

Quebrar um algoritmo criptográfico significa descobrir um meio de obter o texto legível a partir de qualquer texto ilegível. Um algoritmo criptográfico é quebrável se é possível determinar o texto legível ou a chave criptográfica a partir do texto ilegível. O conjunto de métodos matemáticos utilizados para quebrar um algoritmo é chamado ataque ou criptanálise e chamaremos de criptanalista um adversário que efetue ataques ao algoritmo.

Os ataques são classificados da seguinte forma:

Ataque passivo $\mathrm{O}$ criptanalista apenas monitora o canal de comunicação. Este ataque ameaça somente a privacidade da informação

Ataque ativo $\mathrm{O}$ criptanalista tenta excluir, adicionar ou alterar os dados sendo transmitidos. Este ataque ameaça a integridade, a autenticidade e a privacidade dos dados. 
Os ataques passivos podem ser subdivididos em ataques mais especializados. O objetivos dos seguintes ataques são recuperar o texto legível a partir do texto ilegível, ou deduzir a chave de criptografia.

Os tipos de ataque em ordem decrescente de insegurança são:

1. Ataque por só-texto-ilegível: o criptanalista tenta adquirir conhecimento útil à quebra analisando apenas um ou mais textos ilegíveis. Se este tipo de ataque for computacionalmente viável o algoritmo em questão é considerado totalmente inseguro e inútil.

2. Ataque por texto legível conhecido: o criptanalista possui e analisa pares de textos legível e ilegível correspondentes. Neste e nos tipos que ataques a seguir o criptanalista tem acesso ao algoritmo e não é necessariamente um mal-intencionado ou um intruso: pode ser um especialista que objetiva descobrir se o algoritmo é vulnerável a este tipo de ataque, sendo que o algoritmo fora projetado por uma outra pessoa, eventualmente.

3. Ataque por texto legivel escolhido: além do suposto no tipo anterior o criptanalista pode escolher os textos legíveis e obter os textos ilegíveis correspondentes. Ele vai escolher textos legíveis que apresentem alguma característica estrutural que aumente o seu conhecimento do algoritmo e da chave em uso. Com o conhecimento adquirido ele pode deduzir o texto legível correspondente a um texto ilegível novo.

4. Ataque adaptativo por texto legível escolhido: além do suposto no tipo anterior a escolha de um novo texto legível para um criptanalista pode depender dos textos ilegíveis analisados anteriormente. Desta forma a escolha de um novo texto legível é condicionada ao conhecimento já adquirido pela analise dos textos ilegíveis já analisados.

5. Ataque por texto ilegível escolhido: o criptanalista escolhe inicialmente o texto ilegível e então obtém o texto legível correspondente. Supõe-se que o criptanalista tenha acesso apenas ao algoritmo de decriptografia (sem ter acesso a chave) e o seu objetivo é, mais tarde, sem ter mais acesso à decriptografia, ser capaz de deduzir o texto legível correspondente a um novo texto ilegível.

6. Ataque adaptativo por texto ilegível escolhido: além do suposto no tipo anterior a escolha de um novo texto ilegível pelo criptanalista pode depender dos textos ilegíveis analisados anteriormente. Desta forma a escolha de um novo texto ilegível é condicionada ao conhecimento já adquirido pela analise dos textos ilegíveis anteriores.

\subsubsection{Segurança computacional}

Esta medida refere-se ao esforço computacional para quebrar um algoritmo criptográfico. Vamos definir que um algoritmo criptográfico é computacionalmente seguro se o melhor algoritmo conhecido para quebrá-lo requer no mínimo $N$ operações, onde $N$ é um número muito grande. O problema é que nenhum algoritmo criptográfico conhecido pode ser provado como seguro com esta definição. Na prática, um algoritmo é considerado computacionalmente seguro se o melhor algoritmo conhecido para atacá-lo requer uma grande quantidade de tempo para sua computação, o que é diferente de uma prova de sua segurança. Uma outra abordagem que fornece evidência de segurança computacional é redução do algoritmo criptográfico a algum problema conhecido e considerado difícil, como por exemplo, o 
problema de se fatorar números grandes ou o problema do logaritmo discreto. Algoritmos criptográficos deste tipo são algumas vezes considerados "comprovados como seguros", mas a prova de segurança é relativa ao problema, e não uma prova absoluta de segurança. Isto é similar a provar que um problema é NP completo[16].

Considerando esta abordagem, que foi a utilizada pelo NIST no concurso AES, o RC6 foi considerado um algoritmo computacionalmente seguro e neste trabalho ele foi modificado para fortalecê-lo contra um ataque conhecido como criptanálise diferencial. Por este motivo utilizamos o adjetivo forte no algoritmo criptográfico em blocos utilizado.

\subsubsection{Criptanálise Diferencial}

E. Biham e A. Shamir em [1] apresentaram a criptanálise diferencial para algoritmos criptográficos chamados DES-like ciphers ou cifras de Feistel. Neste ataque eles utilizam características, que descrevem o comportamento de diferenças de entrada e saída para um determinado número de iterações consecutivas. A probabilidade da característica de uma iteração é a probabilidade condicional que dada uma certa diferença entre um par de textos de entrada, teremos uma determinada diferença no par de saída da iteração. Lai e Massey [9] observaram que para o sucesso da criptanálise diferencial não seria necessário fixar os valores de entrada e saída das iterações intermediárias em uma característica. Eles apresentaram a noção de diferencial. A probabilidade de um diferencial de $i$ iterações é a probabilidade condicional que dado uma diferença entre pares de entrada na primeira iteração, teremos uma determinada diferença dos pares de saída da $i$-ésima iteração. Note que a probabilidade de um diferencial de $i$ iterações com diferença de entrada $A$ e diferença de saída $B$ é a soma das probabilidades de todas as características cuja diferença de entrada seja $A$ e diferença de saída seja $B$.

Para implementarmos ataques bem sucedidos a cifras de Feistel é necessário a existência características boas, isto é, com alta probabilidade. Por outro lado para garantirmos a segurança de um algoritmo contra criptanálise diferencial nós temos que garantir que não existe nenhum diferencial com probabilidade grande o suficiente para que o ataque seja bem sucedido.

A criptanálise diferencial é um ataque por texto legível escolhido, isto é, o criptanalista é capaz de selecionar textos de entrada e examinar os textos de saída com a finalidade de calcular a chave utilizada. Para a criptanálise o criptanalista irá selecionar pares de entrada que satisfaçam uma determinada diferença de modo que ocorra uma diferença nos pares de saída com alta probabilidade. A medida de diferença utilizada irá depender do algoritmo sendo atacado, por exemplo, no ataque ao DES a medida de diferença é o ou-exclusivo e no caso do RC6 é a subtração de inteiros.

\subsection{Organização da dissertação}

Os demais capítulos desta dissertação estão organizados da seguinte forma. No capítulo dois apresentamos alguns trabalhos que tratam da análise de protocolos criptográficos e algoritmos de criptografia. No capítulo três apresentamos a especificação do TLS e analisamos sua segurança no capítulo quatro. O capítulo cinco apresenta o protocolo para troca de chaves Diffie-Helmann que fará parte do novo conjunto de algoritmos criptográficos para 
uma sessão TLS. No capítulo seis apresentamos e discutimos o RC6 e no capítulo sete estudamos o ataque por criptanálise diferencial ao RC6. No capítulo oito está nossa proposta de modificação do RC6 e sua análise está no capítulo nove.

No capítulo 10 detalhamos a implementação e no capítulo 11 temos a conclusão com um resumo do trabalho e sugestões de futuros trabalhos. Devido a grande quantidade de siglas e termos em inglês na especificação do TLS, temos no apêndice A um glossário de termos e siglas utilizadas. 


\section{Capítulo 2}

\section{Trabalhos relacionados}

Wagner e Schneier [14] analisaram o protocolo SSL 3.0 detalhadamente e as principais falhas encontradas foram a possibilidade de exclusão da mensagem change cipher spec que podia ser enviada opcionalmente antes da mensagem finished e um ataque ativo que leva a utilização de protocolos diferentes para combinação de chaves, sendo possível utilizar os protocolos Diffie-Hellman e RSA para combinação da chave. Destes a especificação TLS 1.0 só corrigiu o primeiro, tornando obrigatório o envio da mensagem change cipher spec antes da mensagem finished. Esta análise foi feita segundo os objetivos de segurança para cada sub-protocolo e dos ataques conhecidos as primitivas criptográficas e aos sub-protocolos utilizados. Esta também foi a abordagem que utilizamos neste trabalho, só que, tendo como base a especificação do TLS 1.0.

Terada, Pinheiro e Koyama são autores de uma nova versão do algoritmo FEAL [13], o FEAL-N(X)S, este difere da versão FEAL-N(X) pela introdução de uma função de troca, que faz a troca das metades de uma seqüência de bits caso o número de bits na sequiência seja ímpar. Esta função de troca aumenta a resistência ao ataque por criptanálise diferencial, porque diminui a probabilidade das características conhecidas. As características estudadas são características que avaliam a diferença entre os pares de entrada e saída utilizando como medida de diferença o ou-exclusivo bit a bit.

A criptanálise diferencial do RC6 é baseada em características que utilizam a diferença de inteiros como medida de diferença. De fato, são utilizados diferencias [9] baseados em características genéricas. Em nosso trabalho mostramos que a função de troca, que tem um baixo custo computacional, também diminui a probabilidade dos diferenciais apresentados em [3]. A introdução desta função foi natural, pois como o FEAL o RC6 tem uma estrutura de cifra de Feistel. Nós chamamos o RC6 modificado de RC6T, isto é, o RC6 com a função de troca. 


\section{Capítulo 3}

\section{Protocolo Transport Layer Security , TLS 1.0}

A versão 1.0 do protocolo Transport Layer Security, TLS 1.0, especifica um protocolo de segurança que provê privacidade de comunicação na Internet. O protocolo permite aplicações Cliente/Servidor manterem comunicação prevenindo a escuta, adulteração ou falsificação das mensagens. Esta especificação não fornece detalhes da definição de serviços ou interfaces com a aplicação. Esta descrição do protocolo TLS baseia-se na especificação [5] desenvolvida a partir da versão do protocolo Secure Sockets Layer, SSL 3.0 publicada pela Netscape Communications Corporation. Apesar das diferenças entre os dois protocolos serem pequenas, o TLS 1.0 não se comunica diretamente com o SSL 3.0, mas tem mecanismos para que sua implementação possa se comunicar com SSL 3.0.

As metas do protocolo TLS, em ordem de prioridades, são as seguintes:

Segurança criptográfica: O TLS deve ser utilizado para o estabelecimento de uma conexão segura entre duas partes;

Interoperabilidade: Implementações diferentes devem ser capazes de se comunicar;

Extensibilidade: O TLS provê uma estrutura onde novos métodos criptográficos possam ser incorporados quando necessário;

Eficiência de processamento: Operações criptográficas têm um alto custo de processamento, particularmente as operações com chaves públicas. O TLS incorporou um esquema de cache de sessão para reduzir o número de conexões que precisam ser estabelecidas desde o início, também reduzindo o tráfego na rede.

\subsection{Arquitetura}

A arquitetura do TLS é definida em duas camadas sobre a pilha do protocolo TCP/IP, veja a figura 3.1. Todas a mensagens originadas nos módulos do protocolo da camada de mensagem, a superior, são passadas para a camada TLS Record. A camada TLS Record fragmenta em registros as mensagens a serem transmitidas aplicando então as transformações criptográficas. Os quatro módulos da camada superior formam a camada de Mensagem. 
Todas as entradas e saídas são da forma definida nestes quatro módulos do protocolo da camada de mensagem. 


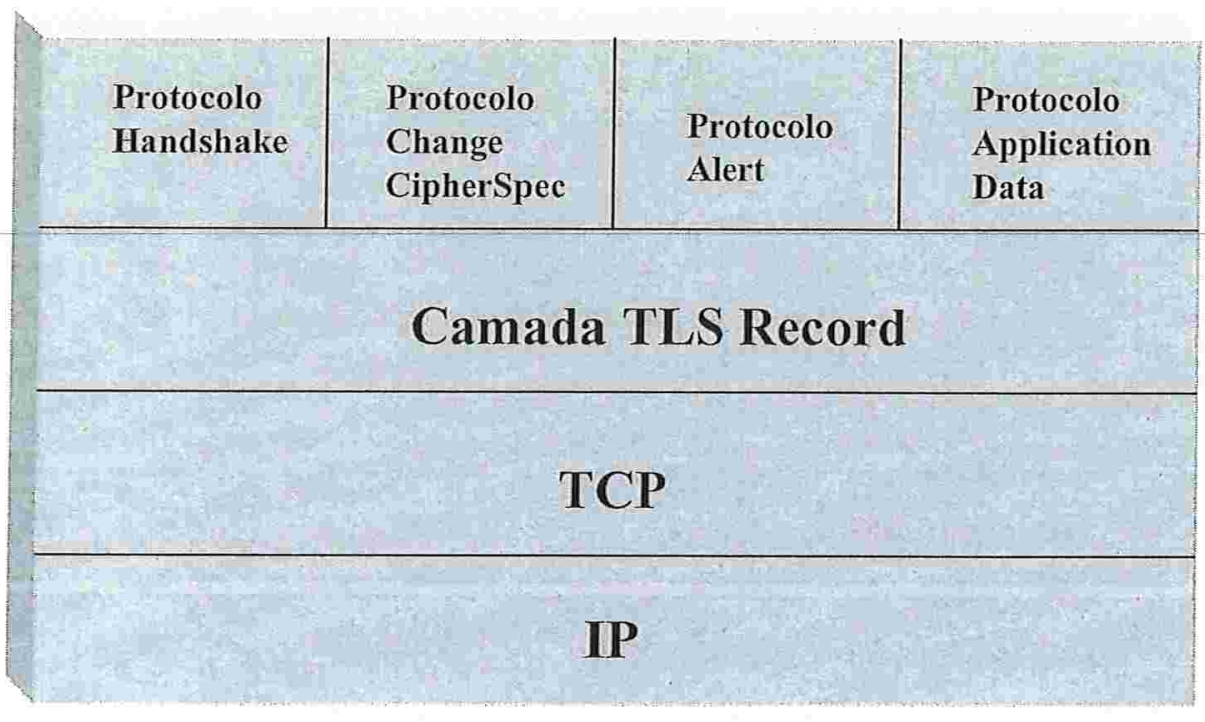

Figura 3.1: Arquitetura do TLS

O protocolo Handshake, detalhado na seção 3.3.3, produz os parâmetros de uma sessão TLS realizando também a autenticação do cliente e servidor. O protocolo Change Cipher Spec, descrito na seção 3.3.1, é constituído de uma única mensagem enviada ao final do Handshake, pelo cliente e servidor, com a finalidade de sinalizar que o conjunto de cifras recém negociadas passarão a ser utilizadas. O protocolo Alert contém mensagens de erro ou de advertência entre os pares da conexão, podendo causar o término da conexão. $\mathrm{O}$ protocolo Application Data contém os dados da aplicação.

O protocolo TLS faz distinção entre sessões e conexões, cada uma com seus respectivos estados, ver seções 3.2.1 e 3.3.3. A conexão TLS é uma extensão do serviço de conexão TCP entre o cliente e o servidor, sendo sempre iniciada pelo cliente. Por outro lado, uma sessão TLS é uma combinação de um conjunto de parâmetros criptográficos e não criptográficos negociadas entre o cliente e o servidor. Quando uma conexão é iniciada, o cliente negocia uma nova sessão ou utiliza os parâmetros de uma sessão previamente negociada, portanto uma sessão pode continuar a existir após o encerramento da conexão em que ela foi criada. Uma sessão também pode conter múltiplas conexões.

A especificação TLS também permite que as aplicações cliente e servidor renegociem os parâmetros da sessão a qualquer momento após a finalização do protocolo handshake inicial. As mensagens com dados da aplicação podem continuar a fluir normalmente durante esta renegociação. Durante as negociações do protocolo handshake, o cliente e o servidor combinam um cipher suite que especifica o algoritmo para troca de chaves, o algoritmo $M A^{1}$ de autenticação e o algoritmo de criptografia. Os parâmetros gerados a partir da cipher suite são chamados cipher spec.

\footnotetext{
${ }^{1}$ As siglas não definidas explicitamente estão definidas no apêndice A.
} 


\subsection{A camada TLS Record}

A camada TLS Record interage diretamente com a pilha de protocolo TCP/IP. A figura 3.2 mostra como os dados da camada de mensagem são processados nesta camada. Os dados são fragmentados em blocos de até $2^{14}$ (16384) bytes. Cada bloco é comprimido, e a compressão não deve ultrapassar $2^{14}+1024$ bytes. Os blocos comprimidos passam por uma função de hash com a chave secreta formando o MAC conforme conjunto de cifras especificados para a sessão corrente. O MAC é adicionado ao final do bloco comprimido e ambos são criptografados segundo o conjunto de cifras da sessão corrente. O resultado final não deve ultrapassar $2^{14}+2048$ bytes. Um cabeçalho é adicionado ao bloco antes de ser passado para a camada TCP. Os registros recebidos sofrem o processo inverso para obtenção dos dados pela aplicação. 


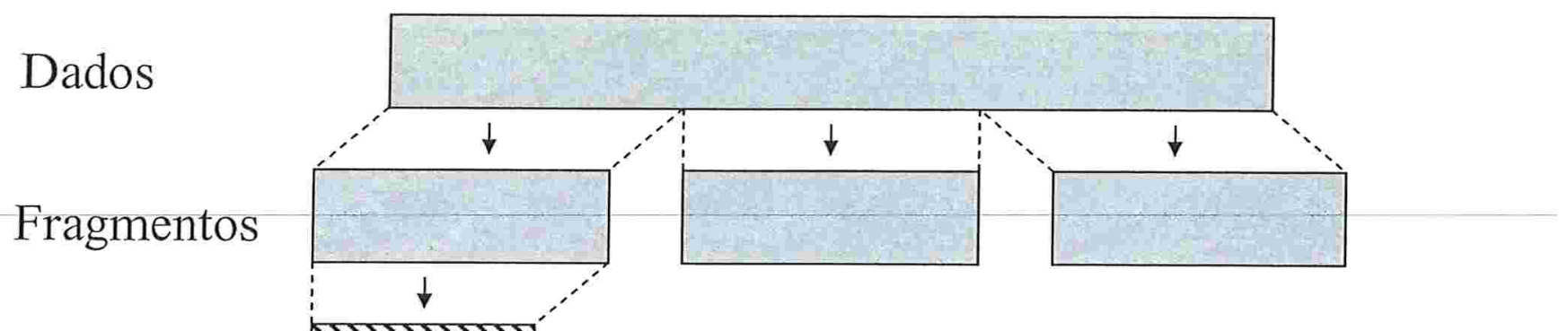

Compressão

Adição MAC

Encriptação

Adição

Cabeçalho

Figura 3.2: Camada TLS Record

\subsubsection{Estados da conexão}

O estado da conexão é o ambiente operacional do protocolo TLS Record. Ele especifica os algoritmos de compressão, criptografia e MAC, bem como os parâmetros necessários para estes algoritmos. Logicamente existem quatro estados em uma conexão: estados correntes de leitura e escrita e estados pendentes de leitura e escrita. Os estados pendentes são os que estão sendo negociados pela protocolo Handshake, mas o protocolo Handshake utiliza os estados correntes da conexão.

Os parâmetros para os estados de leitura e escrita de uma conexão são gerados a partir dos seguintes valores:

Connection end: Se a entidade é considerada cliente ou servidor nesta conexão.

Bulk encryption algorithm: O algoritmo a ser utilizado para criptografia das mensagens. Esta especificação inclui o tamanho da chave, quanto da chave é secreto, se é um algoritmo em bloco ou de fluxo, o tamanho do bloco, e se é considerado um algoritmo para exportação para fora dos Estados Unidos e Canadá segundo as normas Americanas de exportação.

MAC Algorithm: Algoritmo para autenticação de mensagem. Esta especificação inclui o tamanho do hash que é retornado pelo algoritmo MAC. 
Compression algorithm: Algoritmo para compressão de dados. Esta especificação deve conter toda a informação necessária que o algoritmo requeira para realização da compressão.

Master secret: Um segredo de 48 bytes compartilhado entre os pares da conexão.

Client random: Um valor pseudo-aleatório de 32 bytes fornecido pelo cliente para cada conexão.

Server Random: Um valor pseudo-aleatório de 32 bytes fornecido pelo servidor para cada conexão.

A camada TLS Record utilizará os parâmetros para gerar os seguintes ítens :

client write MAC secret: O segredo usado na autenticação MAC nos dados escritos pelo cliente.

server write MAC secret: O segredo usado na autenticação MAC nos dados escritos pelo servidor.

client write key: chave para criptografia dos dados pelo cliente e decriptografia dos dados pelo servidor.

server write key: chave para criptografia dos dados pelo servidor e decriptografia dos dados pelo cliente.

client write IV: Vetor de Iniciação para algoritmos em bloco.

server write IV: Vetor de Iniciação para algoritmos em bloco.

Os parâmetros de escrita do cliente são usados pelo servidor quando recebe e processa os dados do cliente e vice-versa. O algoritmo usado para geração destes ítens a partir dos parâmetros de segurança serão descritos na seção 3.4.3. Cada estado de uma conexão tem os seguintes elementos:

Compression state: Estado corrente do algoritmo de compressão.

Cipher state: Estado corrente do algoritmo de criptografia. Consistindo das chaves programadas para esta conexão. Adicionalmente, para algoritmos em blocos rodando no modo CBC (único modo permitido no TLS), teremos o Vetor de iniciação sendo atualizado pelo último bloco criptografado ou decriptografado conforme os registros são processados. Para algoritmos de fluxo qualquer informação de estado necessária para que o fluxo de dados continue a ser criptografia ou decriptografado.

MAC secret: O segredo do MAC de comprimento igual a saída da função de hash, 16 bytes para a função MD5 e 20 bytes para a função SHA-1. ( ver seção 3.4.1 e glossário para definição das funções MD5 e SHA-1)

Sequence number : Cada estado de uma conexão contém números seqüenciais, que são mantidos separadamente para leitura e escrita. O número seqüencial deve ser posicionado em zero toda vez que estado da conexão se tornar ativo. Os números seqüenciais não devem exceder $2^{64}-1$. O número seqüencial é incrementado a cada registro, o primeiro registro transmitido em uma conexão deve ter o número seqüencial zero. 


\subsection{Protocolo TLS Handshake}

O protocolo TLS Handshake consiste de um conjunto de três sub-protocolos que são utilizados para permitirem aos pares combinar um conjunto de parâmetros para a camada TLS Record, autenticarem-se, instanciarem os parâmetros, e reportarem condições de erros entre si. Estes três sub-protocolos são o Change Cipher Spec, o Alert e o Handshake que serão detalhados nas próximas seções. O protocolo Handshake é responsável pela negociação de uma sessão, cujo estado consiste dos seguintes ítens:

session identifier: Uma seqüência de bytes arbitrária escolhida pelo servidor para identificar uma sessão ativa ou reutilizável.

peer certificate: Certificado $X 509 v 3[3]$ do par na conexão. Este elemento do estado pode ser nulo.

compression method: Algoritmo utilizado para compressão dos dados antes da criptografia.

cipher spec: Especifica o algoritmo de criptografia e um algoritmo MAC. Ele também define atributos criptográficos, tais como o tamanho da saída da função de hash.

master secret: Segredo de 48 bytes compartilhado entre cliente e servidor.

is resumable: Um indicador se a sessão pode ser reutilizada para iniciar novas conexões.

\subsubsection{Protocolo Change Cipher Spec}

O protocolo change cipher spec sinaliza transições de estratégias de segurança. O protocolo consiste de uma única mensagem de um byte com valor um, que é criptografa e comprimida sob o estado corrente da conexão.

A mensagem é enviada por ambos, cliente e servidor, para notificar o receptor que os subseqüentes registros serão protegidos sob o recém negociado CipherSpec. A recepção desta mensagem faz com o receptor instrua a camada TLS Record para copiar imediatamente o estado de leitura pendente para os estado de leitura corrente. Imediatamente após enviar esta mensagem, o transmissor deve instruir a camada TLS Record para copiar o estado de escrita pendente para o estado ativo de leitura, ver seção 3.2.1. A mensagem Change Cipher Spec é enviada durante o protocolo handshake após o acordo dos parâmetros de segurança, mas antes da mensagem de verificação finished ser enviada, ver seção 3.3.3.

\subsubsection{Protocolo Alert}

Um dos protocolos da camada de mensagem aceito pela camada TLS Record é do tipo Alert. Mensagens Alert contém o nível de gravidade da exceção verificada e sua descrição. Mensagens Alert com nível fatal resultam no término imediato da conexão. Neste caso, outras conexões dentro da mesma sessão podem continuar, mas o identificador da sessão deve ser invalidado, para que esta sessão não seja mais reutilizada. Como as demais mensagens, mensagens Alert são criptografadas e comprimidas, como especificada pelo estado corrente da conexão. 


\section{Mensagens Alert de Fechamento da Conexão}

Cliente e servidor devem ter conhecimento que a conexão está terminando. Qualquer uma das partes pode iniciar a troca de mensagens. Qualquer mensagem enviada após a mensagem de fechamento será ignorada.

A mensagem close_notify notifica o receptor que o transmissor não enviará mais mensagens nesta conexão. A sessão não pode ser reutilizada se qualquer conexão for terminada sem a mensagem close_notify com nível de advertência.

É necessário que cada par envie a mensagem close_notify antes de fechar a escrita na conexão. Isto é necessário para que o outro par da conexão responda com uma mensagem close_notify e feche também imediatamente a conexão, descartando qualquer escrita pendente.

Se o protocolo da camada de aplicação utilizando TLS determinar que algum dado possa passar pela camada de transporte após o fechamento da conexão, a implementação TLS deve receber a mensagem de resposta close_notify antes de indicar para camada de aplicação que a conexão TLS terminou. Se a aplicação não for transferir nenhum dado adicional, mas somente for fechar a conexão da camada de transporte, então a implementação pode escolher fechar a conexão de transporte sem esperar pela mensagem de resposta close_notify.

\section{Mensagens de erro}

O tratamento de erro no protocolo TLS Handshake é muito simples. Quando um erro é detectado, quem detectou o erro, envia uma mensagem para o outro par da conexão. Na transmissão ou recepção de uma mensagem alert fatal, ambos os pares fecham a conexão imediatamente. Servidores e clientes têm que descartar qualquer identificador de sessão, chaves e segredos associados à conexão que falhou. As seguintes mensagens de erro são definidas:

unexpected_message: Uma mensagem inadequada foi recebida. Esta mensagem é sempre fatal e nunca deve ocorrer na comunicação de implementações corretas;

bad_record_mac: Mensagem retornada se um registro foi recebido com um MAC incorreto. Esta mensagem é sempre fatal;

decryption_failed: Erro na criptografia. É sempre fatal;

record_overflow: Tamanho do registro excedeu tamanho especificado na fragmentação ou decriptografia;

decompression_failure: Função de descompressão recebeu entrada inadequada. Erro fatal;

handshake_failure: Recepção desta mensagem indica que o transmissor não é capaz de negociar um conjunto de parâmetros segurança aceitável, dada as opções disponíveis. Este erro é fatal.;

bad_certificate: Um certificado não é válido;

unsupported_certificate: Certificado de tipo inválido; 
certificate_revoked: Um certificado foi revogado por seu assinante;

certificate_expired: Certificado expirado ou inválido;

certificate_unknown: Qualquer outro tipo de erro ocorreu no processamento do certificado;

illegal_parameter: Um campo no handshake está fora do intervalo ou inconsistente com outros campos. Erro fatal;

unknown_ca: Uma cadeia de certificados válidos ou uma cadeia parcial foi recebida, mas o certificado não é aceito porque o certificado da CA não pode ser localizado ou não pode ser reconhecido como um trusted CA. Esta mensagem é sempre fatal;

access_denied: Um certificado válido foi recebido, mas quando o controle de acesso foi aplicado, o transmissor decidiu não prosseguir com a negociação. Esta mensagem é sempre fatal;

decode_error: Uma mensagem não pode ser decodificada porque alguns campos estavam fora do intervalo especificado ou o tamanho da mensagem estava incorreto. Esta mensagem é sempre fatal;

decrypt_error: Uma operação criptográfica do protocolo handshake falhou, incluindo a impossibilidade de verificar corretamente uma assinatura, decriptografar uma troca de chaves, ou validar a mensagem finished;

export_restriction: A negociação não está de acordo com as restrições de exportação, por exemplo, tentativa de transferência uma de chave temporária RSA de 1024 bits para o método do handshake RSA_EXPORT. Esta mensagem é sempre fatal;

protocol_version: A versão de protocolo que o cliente está negociando é conhecida, mas não esta disponível. Esta mensagem é sempre fatal;

insufficient_security: Retornada no lugar da mensagem handshake_failure quando a negociação falhou especificamente porque o servidor necessita cifras mais seguras do que as suportadas pelo cliente. Esta mensagem é fatal;

internal_error: Um erro interno não relacionado com o protocolo ocorreu. Esta mensagem é fatal;

user_canceled: O handshake está sendo cancelado por motivos não relacionados com o protocolo. Esta é uma mensagem de advertência, e pode ser seguida por uma mensagem close_notify;

no_renegotiation: Enviada pelo cliente em resposta a uma mensagem hello_request ou pelo servidor em resposta a uma mensagem hello do cliente após um handshake inicial. Esta mensagem é sempre de advertência.

Para todas as mensagens de erro que o nível de alerta não foi especificado explicitamente, o transmissor pode determinar se o erro é fatal ou não, e se uma mensagem alert com nível de advertência é recebida, o receptor deve decidir se trata a mensagem como fatal ou não. 


\subsubsection{Protocolo Handshake}

Os parâmetros criptográficos da sessão são produzidos pelo Protocolo Handshake, que opera no topo da camada TLS Record. Quando um cliente e um servidor iniciam uma comunicação, eles combinam uma versão de protocolo, selecionam os algoritmos criptográficos, opcionalmente autenticam-se mutuamente, e utilizam técnicas de criptografia de chave pública para gerar os segredos compartilhados.

O protocolo Handshake envolve os seguintes passos:

1. Troca das mensagens hello para acordo dos algoritmos, troca dos valores aleatórios, e verificação se a sessão esta sendo reutilizada,

2. Troca dos parâmetros criptográficos que permitem cliente e servidor combinar o premaster secret,

3. Troca de certificados e informação criptográfica que permitem cliente e servidor autenticaremse,

4. Geração do master secret a partir do premaster secret e dos valores aleatórios trocados,

5. Fornecimento dos parâmetros de segurança para camada TLS Record,

6. Permitir que cliente e servidor verifiquem se calcularam os mesmos parâmetros de segurança e que o protocolo handshake ocorreu sem falsificação por algum oponente.

O protocolo handshake pode ser resumido da seguinte maneira: O cliente envia uma mensagem client hello que o servidor deve responder com uma mensagem server hello, ou um erro fatal irá ocorrer e a conexão irá falhar. As mensagens client hello e server hello são usadas para aumento da segurança entre cliente e servidor, e estabelecem os seguintes atributos: Versão do protocolo, identificador da sessão, conjunto de cifras e método de compressão. Adicionalmente dois valores aleatórios são gerados e trocados entre si, ClientHello.random e ServerHello.random.

A troca de chaves utiliza até quatro mensagens: server certificate, server key exchange, client certificate e client key exchange. Novos métodos de troca de chave podem ser criados pela especificação de um formato para estas mensagens, bem como a definição do uso das mensagens de forma a permitir que cliente e servidor combinem um segredo compartilhado. Este segredo deve ser suficientemente longo, atualmente os métodos de troca de chaves definem comprimentos no intervalo de 48 a 128 bytes.

Após as mensagens de hello, o servidor irá enviar seu certificado, caso ele precise ser autenticado. Adicionalmente, uma mensagem server key exchange pode ser enviada, se isto for requerido, caso em que o servidor não tenha um certificado, ou se seu certificado seja somente para assinatura. Caso o servidor seja autenticado, ele pode requisitar um certificado do cliente, se isto for adequado para o conjunto de cifras escolhido. Agora o servidor irá enviar a mensagem server hello done, indicando que a fase de hello esta completa. O servidor irá então esperar pela resposta do cliente. Se o servidor enviou uma mensagem certificate request, o cliente deve enviar a mensagem certificate. A mensagem client key exchange é agora enviada, e o conteúdo da mensagem dependerá do algoritmo de chave pública escolhido entre as mensagens client hello e server hello. Se o cliente enviou 
um certificado com a habilidade de assinatura, uma mensagem digitally-signed certificate verify é enviada para verificação explicita do certificado.

Neste ponto, uma mensagem change cipher spec é enviada pelo cliente, e o cliente copia - Cipher Spec pendente no Cipher spec corrente. O cliente então envia imediatamente a mensagem finished utilizando os novos algoritmos, chaves e segredos. Em resposta, o servidor enviará sua própria mensagem change cipher spec, transferindo o cipher spec de pendente para corrente enviando a mensagem finished sob o novo cipherspec. Então, o protocolo handshake está completo e cliente e servidor podem começar a trocar mensagens da camada de aplicação. ( Ver figura 3.3.) 


\begin{tabular}{|c|c|}
\hline Cliente & \multirow{3}{*}{$\begin{array}{l}\text { Servidor } \\
\longrightarrow \text { Acordo dos algoritmos, versão } \\
\text { protocolo e id da sessão }\end{array}$} \\
\hline ClientHello & \\
\hline ServerHello & \\
\hline ServerCertificate & \multirow{7}{*}{$\begin{array}{l}\text { Combinação dos parâmetros } \\
\text { criptográficos para geração } \\
\text { do material secreto e } \\
\text { autenticação reciproca }\end{array}$} \\
\hline ServerKeyExchange & \\
\hline CertificateRequest & \\
\hline ServerHelloDone & \\
\hline ClientCertificate & \\
\hline ClientKeyExchange & \\
\hline CertificateVerify. & \\
\hline [ChangeCipherSpec] & \multirow{6}{*}{$\begin{array}{l}\text { Troca para nível de segurança } \\
\text { combinado e verificação se } \\
\text { cliente e } \\
\text { servidor calcularam seu } \\
\text { parâmetros } \\
\text { sem adulteração }\end{array}$} \\
\hline Finished & \\
\hline [ChangeCipherSpec] & \\
\hline Finished & \\
\hline Dados da aplicação & \\
\hline & \\
\hline
\end{tabular}

Figura 3.3: Fluxo de mensagens para um handshake completo. A mensagem ChangeCipherSpec entre colchetes é um protocolo independente, e as mensagens com asterisco são opcionais.

Quando um cliente e servidor decidem reutilizar uma sessão ou duplicar uma sessão existente o fluxo de mensagens é o seguinte: O cliente envia uma mensagem ClientHello usando o identificador da sessão que será reutilizada. O servidor verifica se existe o identificador em seu cache de sessão. Se existir, e o servidor desejar restabelecer a conexão sob o estado especificado pela sessão, ele enviará uma mensagem ServerHello com o mesmo identificador da sessão. Neste ponto, cliente e servidor devem enviar mensagens change cipher spec e finished. Uma vez que o restabelecimento está completo, cliente e servidor podem começar a trocar mensagens da camada de aplicação.( Veja figura 3.4). Caso o identificador não seja encontrado no cache, o servidor gera um novo identificador para a sessão e cliente e servidor realizam um handshake completo.

\section{Mensagens HELLO}

As mensagens da fase Hello são usadas para acordo do nível de segurança entre cliente e servidor. Quando uma nova sessão começa, o estado da sessão quanto aos algoritmos de criptografia, hash e compressão têm valor $N U L L$, significando que estas operações são 


\section{Cliente}

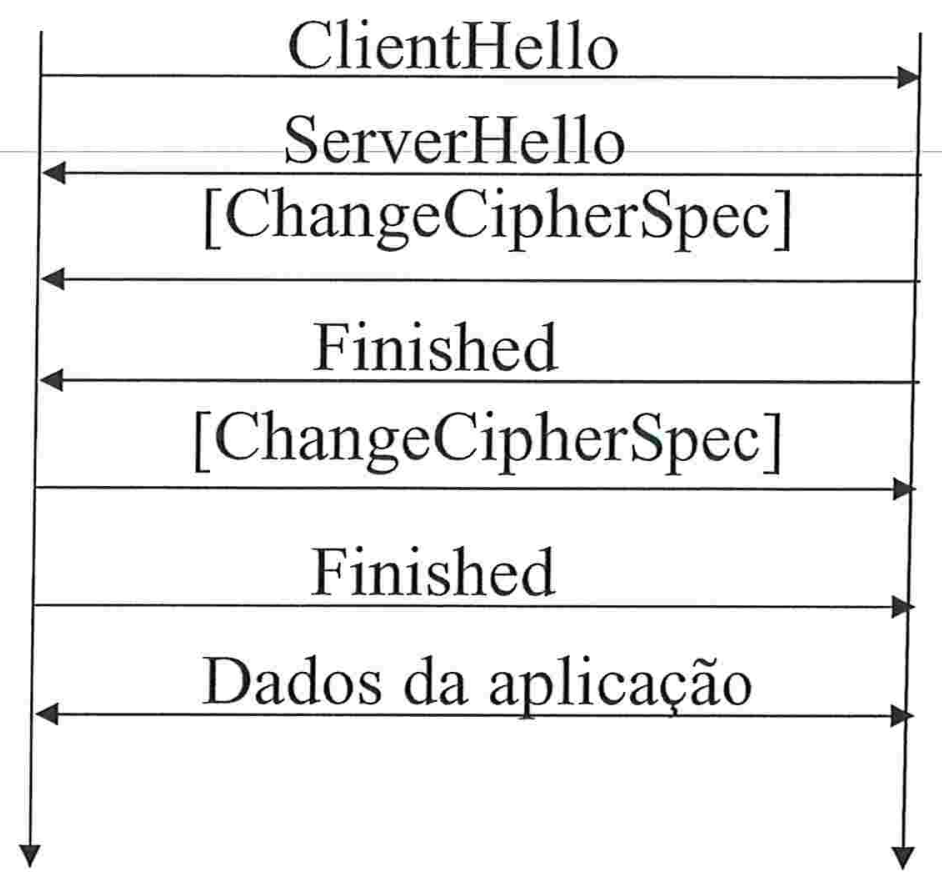

Servidor

Figura 3.4: Fluxo de mensagens para um handshake abreviado.

iguais a operação identidade. O estado corrente da conexão é utilizado para as mensagens de renegociação. A seguir temos as descrições das mensagens HELLO:

Mensagem Hello Request Esta mensagem pode ser enviada pelo servidor a qualquer momento, informando o cliente, que este deve iniciar um novo processo de negociação. A mensagem será ignorada caso o cliente esteja correntemente negociando uma sessão. O cliente pode ignorar a mensagem quando não quiser renegociar a sessão ou responder com a mensagem de alerta no_renegotiation. Caso o servidor envie uma mensagem Hello Request e não receba como resposta uma mensagem Client Hello ele poderá encerrar a conexão enviando uma de mensagem de alerta fatal.

Mensagem Client Hello Quando o cliente inicia a conexão com o servidor, a mensagem Client Hello é a primeira mensagem enviada. Esta mensagem também pode ser enviada em resposta a uma mensagem Hello request, ou por iniciativa própria, quando quiser renegociar os parâmetros de segurança. A mensagem contém os seguintes ítens:

- Versão do protocolo, sendo a maior versão que é aceita pelo cliente.

- Um valor aleatório formado pelo horário no formato padrão UNIX, com 32 bits, e 28 bytes aleatórios gerados.

- Um valor de comprimento variável, entre 0 e 32 bytes, contendo o identificador da sessão. Caso este valor não seja vazio, o valor contém o valor de identificação 
de uma sessão previamente negociada entre cliente e servidor, cujos parâmetros de segurança o cliente queira reutilizar.

- A lista dos Cipher Suites aceitos pelo cliente ordenada segundo a preferência do cliente.

- A lista de algoritmos de compressão por ordem de preferência.

Mensagem Server Hello A mensagem Server Hello é enviada pelo servidor em resposta a mensagem do cliente Client Hello sempre que consegue encontrar um conjunto aceitável de algoritmos, caso contrário, ele envia uma mensagem de alerta failure handshake. A mensagem contém os seguintes itens:

- Versão do protocolo, sendo a maior aceita pelo servidor que não supere a sugerida pelo cliente na mensagem Client Hello.

- Um valor aleatório como o gerado pelo cliente, mas o mesmo deve ter um valor diferente e ser gerado independentemente.

- Um valor de comprimento variável, entre 0 e 32 bytes, contendo o identificador da sessão. Este valor pode ser o mesmo da mensagem Hello Client quando a sessão estiver sendo reutilizada ou um novo valor gerado pelo servidor para uma negociação completa.

- A Cipher Suite selecionada pelo servidor na lista enviada pelo cliente. Para sessões reutilizadas conterá o Cipher Suite do estado da sessão.

- O algoritmo de compressão escolhido da lista enviada pelo cliente ou o do estado da sessão sendo reutilizada.

\section{Mensagem Server Certificate}

Um certificado deve ser enviado sempre que o método escolhido para troca de chaves não for anônimo. Esta mensagem é enviada imediatamente após a mensagem Server Hello.

O tipo do certificado deve ser apropriado ao algoritmo da cipher suite escolhida, sendo geralmente um certificado $X .509 v 3[2]$. Ele deve conter uma chave adequada ao método de troca de chaves, como descrito na tabela 3.1

\section{Mensagem Server Key Exchange.}

Esta mensagem deve ser enviada imediatamente após a mensagem Server Certificate, ou após a mensagem Server Hello, caso seja uma negociação anônima.

A mensagem Server Key Exchange é enviada pelo servidor somente quando a mensagem Server Certificate não contém dados suficientes que permitam o cliente trocar o premaster secret. Isto ocorre para os seguintes métodos: RSA_EXPORT (Se a chave for maior que 512 bits), DHE_DSS, DHE_DSS_EXPORT, DHE_RSA, DHE_RSA_EXPORT e DH_anon.

Não é permitido mandar a mensagem Server Key Exchange para os seguintes métodos de troca de chaves: RSA, RSA_EXPORT ( Se a chave for menor ou igual a 512 bits), DH_DSS e DH_RSA.

Esta mensagem contém informação criptográfica que permite ao cliente comunicar o premaster secret, consistindo da chave pública RSA para criptografia do premaster secret, ou os 


\begin{tabular}{|l|l|}
\hline Algoritmo para troca de chaves & Tipo de chave do Certificado \\
\hline RSA & $\begin{array}{l}\text { Chave pública RSA. O certificado deve permitir } \\
\text { que a chave seja usada para criptografia. }\end{array}$ \\
\hline RSA_EXPORT & $\begin{array}{l}\text { Chave pública RSA com comprimento maior que } \\
512 \text { bits que pode ser utilizada para assinatura, } \\
\text { ou chave de comprimento menor ou igual a 512 } \\
\text { bits que pode ser utilizada para criptografia ou } \\
\text { assinatura. }\end{array}$ \\
\hline DHE_DSS & Chave pública DSS. \\
\hline DHE_DSS_EXPORT & Chave pública DSS. \\
\hline DHE_RSA & $\begin{array}{l}\text { Chave pública RSA que pode ser usada para } \\
\text { assinatura. }\end{array}$ \\
\hline DHE_RSA_EXPORT & $\begin{array}{l}\text { Chave pública RSA que pode ser usada para } \\
\text { assinatura. }\end{array}$ \\
\hline DH_DSS & $\begin{array}{l}\text { Chave Diffie-Hellman. O algoritmo utilizado } \\
\text { para assinar o certificado deve ser o DSS. }\end{array}$ \\
\hline DH_RSA & $\begin{array}{l}\text { Chave Diffie-Hellman. O algoritmo utilizado } \\
\text { para assinar o certificado deve ser o RSA. }\end{array}$ \\
\hline DH_anon & $\begin{array}{l}\text { No método Diffie-Hellman anônimo não há cer- } \\
\text { tificado. }\end{array}$ \\
\hline
\end{tabular}

Tabela 3.1: Métodos de troca de chaves e tipo de chaves contidas nos certificados

parâmetros públicos do Diffie-Hellman com os quais o cliente pode completar a combinação do premaster secret.

\section{Mensagem Server Hello Done}

Esta mensagem é enviada pelo servidor indicando o fim das mensagens da fase hello do servidor e sinaliza ao cliente que este pode dar prosseguimento a sua fase de troca de chaves.

\section{Mensagem Client Certificate}

Esta é a primeira mensagem que o cliente pode enviar após o recebimento da mensagem hello done, e é enviada somente no caso de solicitação de um certificado por parte do servidor. Caso o cliente não tenha um certificado adequado, ele pode mandar uma mensagem vazia, mas se o servidor exigir autenticação do cliente, ele enviará uma mensagem fatal de alerta, terminando a conexão.

\section{Mensagem Client Key Exchange}

Esta mensagem é sempre enviada pelo cliente. Ela é enviada após a mensagem Client Certificate, quando esta for enviada, ou após a mensagem Server Hello Done. 
Com esta mensagem o premaster secret é compartilhado por ambas as partes, através da transmissão direta pelo cliente utilizando a chave pública RSA, ou pela transmissão dos parâmetros do Diffie-Hellman que permitirá a geração do premaster secret por ambas as partes.

\section{Mensagem Certificate Verify}

Esta mensagem é utilizada para a verificação explícita do certificado enviado pelo cliente. A mensagem somente é enviada quando o certificado enviado pelo cliente tem a capacidade de assinatura. Os dados assinados na mensagem são a concatenação de todas as mensagens enviadas e recebidas durante o protocolo handshake trocadas até o momento, exceto a própria mensagem.

\section{Mensagem Finished}

A mensagem finished é enviada imediatamente após a mensagem change cipher spec para se verificar se o processo de autenticação e troca de chaves foi bem sucedido. Ela é a primeira mensagem protegida com os parâmetros de segurança recém negociados. O receptor da mensagem deve verificar se o seu conteúdo está correto. Uma vez que uma parte da conexão enviou e recebeu a mensagem finished, ele poderá começar a enviar e receber dados da aplicação através da conexão.

Os dados enviados na mensagem finished são a concatenação de todas as mensagens do protocolo handshake exceto a própria mensagem. As mensagens cipher change spec e alert não fazem parte do protocolo handshake e não estarão contidas na mensagem finished.

\section{Certificado para Chave Pública}

Certificado para chave pública é uma forma de armazenamento e distribuição de chaves públicas, através de canais de comunicação inseguros, de modo que alterações em seu conteúdo possam ser verificadas. O objetivo é disponibilizar a chave pública de uma entidade para terceiros e estes possam verificar sua autenticidade e validade.

Um certificado para chave pública é uma estrutura de dados com uma parte para os dados e outra parte para assinatura digital ( ver glossário). A parte de dados contém, pelo menos, a chave pública e uma identificação da entidade associada. A parte de assinatura consiste da assinatura digital por autoridade certificadora da parte de dados. Autoridades certificadoras são entidades confiáveis cuja assinatura garante a autenticidade da chave pública.

O protocolo TLS utiliza certificados com padrão X.509 [2]. Este padrão define qual informação deve estar contida no certificado e como ela é formatada. Todos certificados X509 contém as seguintes informações:

Versão : Identifica a versão do padrão X509 sendo utilizada por este certificado. Atualmente existem três versões.

Número de série: A entidade que criou o certificado é responsável pela atribuição de um número de série para distinção de outros certificados emitidos pela mesma. Esta informação é utilizada de diversas maneiras, por exemplo, quando o certificado é revogado seu número de série é colocado em uma lista de certificados revogados . 
Identificador do algoritmo para assinatura: Identifica o algoritmo utilizado pela CA para assinatura do certificado.

Nome do emissor: O nome no padrão X500 da entidade que assina o certificado, geralmente uma CA. A utilização do certificado implica na confiança da entidade que assina o certificado.

Período de validade: Este período é descrito por uma data de início e uma data de fim da validade.

Nome do usuário do certificado: Nome da entidade cujo certificado identifica a chave pública. Este nome utiliza o padrão X500 e deve ser único através da Internet.

Informação da chave pública: Chave pública, algoritmo criptográfico associado a chave e parâmetros necessários.

A versão 1 do padrão X509 está disponível desde 1988 e contém todos os campos descritos acima.

A versão 2 do padrão $X 509$ (1993) introduziu o conceito de identificadores únicos para o usuário e o emissor do certificado para que seja possível a reutilização dos nomes do usuário e emissor do certificado.

A versão 3 (1996) acrescentou um campo extensão, onde qualquer um pode definir uma extensão e inclui-la no certificado. Algumas extensões comuns atualmente são: KeyUsage que restringe o tipo de utilização da chave, por exemplo, somente para assinatura, e AlternativeNames que permite que a chave seja associada a outras identidades, como por exemplo, nomes de DNS, endereços de correio eletrônico e endereços de IP. Extensões também podem ser marcadas como críticas para indicar que sua utilização é obrigatória. Por exemplo, se a extensão KeyUsage estiver marcada como critica e seu valor for somente para assinatura ele será rejeitado para criptografia.

\subsection{Geração do Material Secreto}

O resultado de qualquer um dos algoritmos de troca de chaves é chamado premaster secret e é utilizado para geração do master secret. Na figura 3.5 podemos observar os passos da geração do material secreto. 


\title{
RSA \\ Diffie-Hellman
}

\author{
$\downarrow$ \\ Pre-Master-Secret

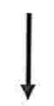 \\ Master Secret \\ $\downarrow$ \\ Key-Block Material \\ $\downarrow$ \\ Keys/IV
}

Figura 3.5: Geração do material secreto compartilhado

\subsubsection{HMAC e a Função pseudo-aleatória}

Uma série de operações nas camadas de protocolo TLS Record e Handshake requerem uma codificação MAC utilizando uma chave, isto é, um resumo seguro dos dados protegidos por um segredo. Falsificar a codificação MAC é impraticável sem o conhecimento do segredo. A construção utilizada no TLS é a HMAC, e está descrita em [8] .

HMAC pode ser utilizada com uma variedade de algoritmos de hash. TLS utilizao no protocolo handshake com dois diferentes algoritmos: MD5 e SHA-1, denotados como HMAC_MD5(segredo, dados) e HMAC_SHA(segredo,dados). Outros algoritmos podem ser definidos nos cipher suites, mas nesta versão são utilizados o MD5 e SHA-1 na descrição do protocolo Handshake.

Uma construção adicional é necessária para expansão dos segredos em blocos de dados para geração ou validação de chaves. Esta construção é chamada função pseudo-aleatória, $P R F$. A PRF tem como entrada um segredo, uma semente e um rótulo de identificação e produz uma saída de tamanho arbitrário.

Para tornar a função o mais segura possível, são utilizados dois algoritmos de hash de modo se garanta a segurança se pelo menos um algoritmo permaneça seguro.

Primeiro, é definida uma função de expansão, P_hash(segredo, dados) que utiliza somente um algoritmo de hash para expandir um segredo e uma semente para qualquer 
tamanho que se queira, ver figura 3.6.

Entrada: Um segredo e uma semente.

Saída: Cadeia de tamanho arbitrário.

$P \_$hash $($segredo, semente $)=H M A C_{-}$hash $($segredo, $A(1)+$ semente $)+$ $H M A C \_h a s h($ segredo, $A(2)+$ semente $)+$ $H M A C$ _hash (segredo, $A(3)+$ semente $)+\ldots$

onde + indica concatenação.

$\mathrm{A}()$ é definido como :

$\mathrm{A}(0)=$ semente $\mathrm{e}$

$\mathrm{A}(\mathrm{i})=$ HMAC_hash(segredo, A(i-1))

Figura 3.6: Função de expansão

A função $p_{-}$hash pode ser iterada quantas vezes forem necessárias para conseguir a quantidade de dados requerida. Por exemplo, se for utilizada a função $P_{-} S H A-1$ para conseguir gerar 64 bytes, ela deve ser iterada 4 vezes, criando 80 bytes, sendo os últimos 16 bytes descartados.

A $P R F$ do TLS é criada dividindo-se o segredo em duas metades, e utilizando-se uma metade com o $P_{-} M D 5$ e a outra metade com o $P_{-} S H A-1$, então é realizada a operação ouexclusivo com as duas saídas das funções de expansão. $S 1$ e $S 2$ são cada uma das metades do segredo e têm o mesmo tamanho. $S 1$ é a primeira metade e $S 2$ a Segunda. O comprimento de $S 1, L S 1$, e o comprimento de $S 2, L S 2$, são dados por , $L S 1=L S 2=\lceil L S / 2\rceil$, onde $L S$ é o tamanho do segredo. Deste modo, caso o segredo tenha um número ímpar de bytes, o último byte de $S 1$ será igual ao primeiro byte de $S 2$.

A função $P R F$ é então definida como a mistura, através de um ou-exclusivo, de dois fluxos de dados pseudo-aleatórios, dada por:

$P R F($ segredo, rotulo, semente $)=P_{-} M D 5(S 1$, rotulo+semente $) \oplus P_{-} S H A-1(S 2$, rotulo+semente $)$.

O rótulo é uma cadeia de caracteres ASCII de tamanho arbitrário. Pelo fato da função $M D 5$ produzir uma saída de 16 bytes e a função $S H A-1$ produzir 20 bytes o número de iterações não alinhados, para gerar 80 bytes é preciso iterar a função MD5 cinco vezes e a função SHA-1 quatro vezes.

\subsubsection{Cálculo do Master Secret}

Para todos os métodos de troca de chave, o mesmo algoritmo é utilizado para a conversão do pre_master_secret no master_secret. O pre_master_secret deve ser removido da memória após o cálculo do master secret. O cálculo é feito pela seguinte função:

master_secret $=$ 
PRF(pre_master_secret, "master secret", ClientHello.random + ServerHello.random).

$\mathrm{O}$ master secret tem sempre exatamente 48 bytes de comprimento. O comprimento do premaster secret varia conforme o método utilizado para a troca de chaves.

\section{Troca de chaves utilizando o RSA}

Quando o RSA é utilizado para autenticação e troca de chaves, o premaster secret de 48 bytes é gerado pelo cliente, criptografado com a chave pública do servidor e é enviado para o servidor. O servidor usa sua chave secreta para decriptografar o premaster secret, então cliente e servidor calculam o master secret, como especificado na seção 3.4.2.

\section{Troca de chaves utilizando o Diffie-Hellman}

O cálculo convencional do Diffie Hellman é realizado. A chave negociada é então utilizada como premaster secret, calculando-se o master secret como especificado na seção 3.4.2.

Os parâmetros do Diffie-Hellman são sempre especificados pelo servidor, e podem ser efêmeros ou contidos no certificado do servidor.

\subsubsection{Cálculo das chaves}

O protocolo TLS Record requer um algoritmo para geração de chaves, vetores de iniciação e o segredo para o MAC, a partir dos parâmetros de segurança fornecidos pelo protocolo Handshake.

O master secret é passado para uma função de hash gerando uma seqüência de bytes que são atribuídos às chaves, aos segredos do MAC e vetores de iniciação. CipherSpecs necessitam um segredo MAC para escrita do cliente, um segredo MAC para escrita do servidor, uma chave para escrita do cliente, uma chave para escrita do servidor, um vetor de iniciação para escrita do cliente e um vetor de iniciação para escrita do servidor, que serão gerados a partir do master secret nesta ordem. A figura 3.7 mostra a geração do material secreto.

Os parâmetros client_write_IV e server_write_IV são gerados somente para cifras que não podem ser exportadas. Para cifras exportáveis, os vetores de iniciação são calculados mais tarde, sendo também necessário um processamento adicional para o cálculo das chaves de escrita finais. Ver figura 3.8. 
Para geração do material secreto, calcule:

key_block $=P R F($ SecurityParameters.master_secret,

"key expansion",

SecurityParameters.server_random+

SecurityParameters.client_random).

Até que material suficiente tenha sido gerado. Então o key_block é particionado como segue:

client_write_MAC_secret[SecurityParameters.hash_size], server_write_MAC_secret[SecurityParameters.hash_size], client_write_key[SecurityParameters.key_material_length], server_write_key[SecurityParameters.key_material_length], client_write_IV [SecurityParameters.IV_size], server_write_IV[SecurityParameters.IV_size].

Figura 3.7: Geração do material secreto

final_client_write_key $=P R F($ SecurityParameters.client_write_key,

"clientwritekey",

SecurityParameters.client_random+

SecurityParameters.server_random);

final_server_write_key $=P R F\left(\right.$ SecurityParameters.server_write $e_{k} e y$,

"serverwritekey",

SecurityParameters.client_random+

SecurityParameters.server_random);

$i v_{-}$block = PRF(" ", "IVblock", SecurityParameters.client_random + SecurityParameters.server_random);

client_write_IV [SecurityParameters.IV_size]

server_write_IV [SecurityParameters.IV_size]

Figura 3.8: Geração das chaves finais e vetores de iniciação para algoritmos exportáveis 


\section{Capítulo 4}

\section{Análise do Protocolo TLS 1.0}

O protocolo TLS 1.0 foi projetado para estabelecer uma conexão segura entre um cliente e um servidor comunicando-se através de um canal não seguro. A análise do protocolo será feita avaliando-se os objetivos de segurança que o protocolo disponibiliza para comunicação entre duas partes, e também, quanto a capacidade de resistir aos ataques a protocolos.

Os objetivos de segurança do TLS 1.0 são os seguintes:

1. Privacidade na comunicação: Os dados passados pela conexão são secretos e só conhecidos pelos pares da conexão.

2. Autenticação das entidades: Os pares envolvidos em uma conexão podem autenticaremse mutuamente.

3. Autenticação de mensagens: Garantia da integridade das mensagens trocadas entre os pares.

4. Proteção contra repetição de mensagens: Mensagens não poderão ser reutilizadas ou reordenadas.

5. Segurança do protocolo para combinação das chaves: Resistência aos ataques conhecidos a protocolos de troca de chaves.

\subsection{Camada TLS Record}

\subsubsection{Privacidade}

O Protocolo TLS criptografa todos os dados da camada de aplicação com um algoritmo bulk cipher utilizando a chave negociada pelo protocolo handshake. Existe uma grande variedade de algoritmos fortes de criptografia no conjunto padrão de ciphers suites, além disso o protocolo permite a criação de novas cipher suites com outros algoritmos, para que se possa aumentar o nível de segurança desejado.

O nível de segurança pode ser ajustado segundo a necessidade e o conjunto de algoritmos aceitos pelo cliente e servidor. Vale também comentar, que existe uma série de aplicações desenvolvidas de acordo com as restrições à exportação de algoritmos criptográficos para fora dos Estados Unidos e Canadá, que utilizam algoritmos enfraquecidos como o DES com chave de 40 bits que não garantem a privacidade da comunicação. 


\subsubsection{Autenticação de Mensagens.}

A construção utilizada para autenticação é conhecida como HMAC [8]. Esta construção é superior a utilizada pelo protocolo SSL 3.0, como notou Schneier [14], existindo evidencias teóricas quanto a sua segurança.

O HMAC pode ser utilizado com uma variedade de algoritmos de hash, o TLS utiliza o HMAC com dois algoritmos diferentes o MD5 e o SHA-1. Em 1996, Hans Dobbertin [7] implementou um ataque que gerou colisões na função de compressão utilizada pelo MD5. Devido a esta fraqueza no algoritmo MD5, seria recomendável a utilização de outros algoritmos no HMAC. O conjunto de algoritmos criptográficos introduzido em nossa implementação utiliza a função de hash SHA para autenticação de mensagens.

\subsubsection{Ataque por Repetição de mensagens}

O TLS 1.0 protege ataques por repetição de mensagens pela inclusão explícita de um número seqüencial nos dados que são passados pelo MAC. Este mecanismo também permite a proteção contra reordenação, atraso e exclusão de dados.

\subsection{Protocolo TLS Handshake}

\subsubsection{Ataque por enfraquecimento do Cipher Suite}

Este ataque é efetuado pela edição da lista de ciphersuites enviados na mensagem não protegida Client Hello e é evitado no TLS pela mensagem finished que contém todas as mensagens trocadas durante o handshake devidamente protegidas pelo MAC.

\subsubsection{Algoritmos diferentes para troca de chaves}

Este ataque foi descrito por Schneier [14] em sua análise do protocolo SSL 3.0 e não foi feita nenhuma alteração ou comentário na especificação do protocolo TLS 1.0. O protocolo TLS 1.0 permite que o servidor trabalhe com chaves temporárias para os protocolos de troca de chaves RSA ou Diffie-Hellman. Isto somente é permitido quando o certificado fornecido pelo servidor tem somente capacidade para assinatura. A assinatura protege somente os campos com os parâmetros dos algoritmos mas não o campo com o tipo do algoritmo utilizado. Este ataque pode ser evitado por uma implementação que faça uma validação cuidadosa do comprimento dos parâmetros recebidos na mensagem Server Key Exchange.

Caso a implementação não faça a devida verificação, um ataque ativo pode ser implementado com a alteração do cipher suite nas mensagens Hello do cliente e do servidor, fazendo com que o servidor utilize o algoritmo Diffie-Hellman com chaves temporárias e o cliente utilize o algoritmo RSA com chaves temporárias. Desta forma, o número primo $p$ e o gerador $g$ do algoritmo Diffie-Hellman enviados pelo servidor serão interpretados pelo cliente como o módulo e expoente do RSA respectivamente. Interceptando-se o premaster secret criptografado pelo cliente, $k^{g} \bmod (p)$, a recuperação de $k$ é feita pelo cálculo da $g$-ésima raiz, o que pode ser feito de maneira eficiente uma vez que $p$ é primo. Agora que o premaster secret foi descoberto é fácil falsificar o resto das mensagens do handshake, inclusive a mensagem finished. Veja o resumo do ataque na figura 4.1. Em nossa implementação 
validaremos o tamanho do módulo RSA e também faremos um rápido teste de primalidade do mesmo.

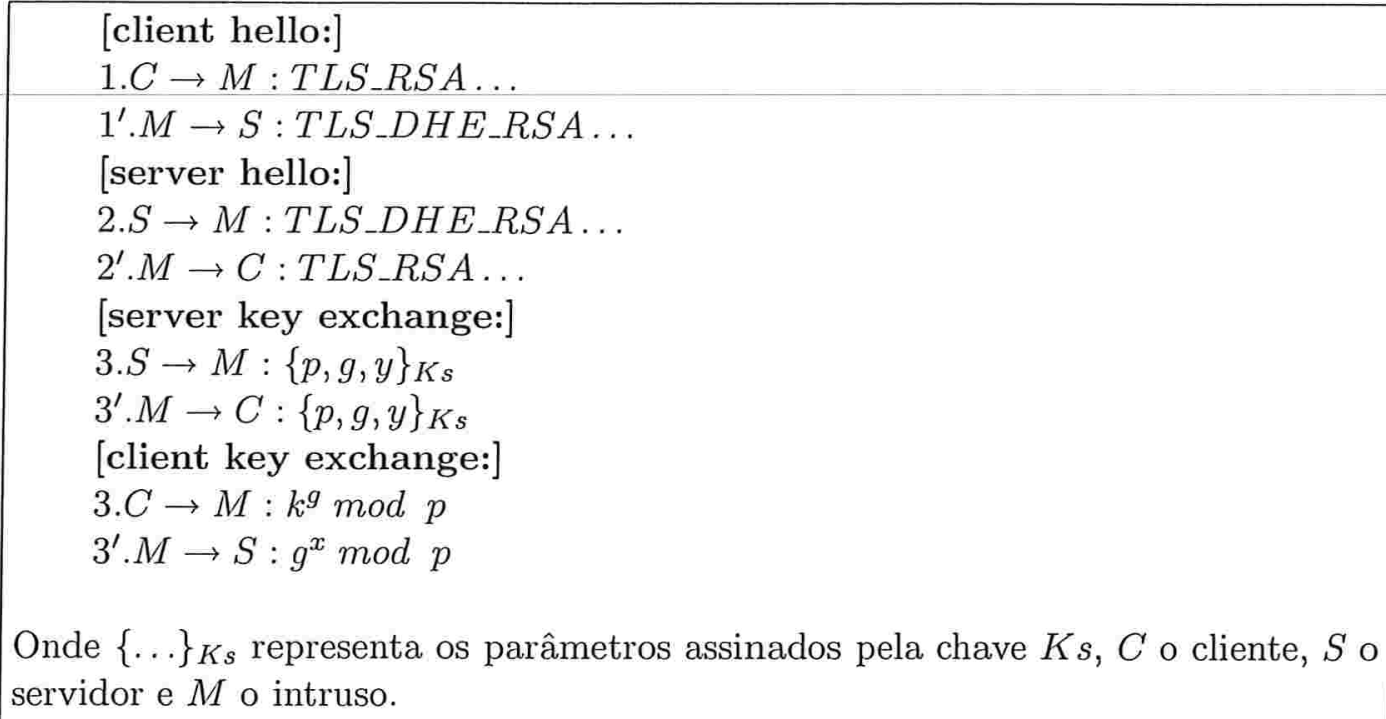

Onde $\{\ldots\}_{K s}$ representa os parâmetros assinados pela chave $K s, C$ o cliente, $S$ o servidor e $M$ o intruso.

Figura 4.1: Resumo do ataque por algoritmos diferentes para troca de chaves

\subsubsection{Diffie-Hellman anônimo}

Quando o servidor não possuir um certificado é possível estabelecer a conexão utilizando o Diffie-Hellman anônimo para a troca de chaves. Neste caso, a comunicação ficará vulnerável ao conhecido ataque $M a n$-in-the-middle descrito na seção 5.2.1 do próximo capítulo. 


\section{Capítulo 5}

\section{Protocolo para Troca de Chaves Diffie-Hellman}

\subsection{Problema do Algoritmo Discreto}

Alguns ${ }^{1}$ criptossistemas são baseados na dificuldade computacional do Problema do Logaritmo Discreto que é o seguinte:

Dados um primo $p$ e inteiros $g, t: 0<g, t<p$, calcular um inteiro

$s$ tal que $t=g^{s} \bmod p$.

Quando $p$ é relativamente longo, não se conhece algoritmo de tempo polinomial para resolução deste problema.

\subsection{Diffie-Hellman}

O protocolo para combinação de chave secreta foi publicado por W. Diffie e M. Hellman em 1976 [6]. Este protocolo pode ser "quebrado" por um intruso ativo, mas uma pequena modificação torna o protocolo seguro contra este ataque.

A figura 5.1 descreve os passos do protocolo para combinação de chave secreta entre as entidades $A$ e $B$. Os números inteiros $p$ e $g$ são conhecidos publicamente, sendo $p$ um primo longo e $g$ tal que $0<g<p$ gerador de $Z_{p}^{*}$.

\subsubsection{Ataque ativo do tipo "man-in-the-middle"}

Este ataque considera um intruso que se coloca na linha de comunicação entre as duas entidades executando o protocolo para combinação de chaves, e age de uma forma ativa, isto é, não apenas escuta a linha mas também insere alguma informação que lhe traga alguma vantagem.

No caso do protocolo Diffie-Hellman, uma entidade $C$ consegue se passar pela entidade $B$ perante a entidade $A$, e também se passar por $A$ perante $B$, da seguinte maneira:

\footnotetext{
${ }^{1}$ As definições deste capítulo foram retiradas de [17].
} 
1.A escolhe um número aleatório $S_{A}, 1 \leq S_{A} \leq p-2$.

2.B escolhe um número aleatório $S_{B}, 1 \leq S_{B} \leq p-2$.

3. $A$ calcula $t_{A}=g^{S_{A}} \bmod p$ e o envia para $B$.

4. $B$ calcula $t_{B}=g^{S_{B}} \bmod p$ e o envia para $A$.

5.A calcula $\left(t_{B}\right)^{S_{A}} \bmod p=K_{A B}$

6. $B$ calcula $\left(t_{A}\right)^{S_{B}} \bmod p=K_{A B}$

Figura 5.1: Protocolo para Combinação de Chave Secreta Diffie-Hellman

1. Quando $A$ envia $t_{A}, C$ bloqueia $t_{A}$ e envia para $B$ um outro inteiro $t_{C}=g^{S_{C}} \bmod p$.

$$
A \rightarrow t_{A} \rightarrow C \rightarrow t_{C} \rightarrow B
$$

2. $B$ recebe $t_{C}$ como se fosse $t_{A}$ e faz os cálculos de acordo com o protocolo, estabelecendo a chave $K_{B C}$ com $C$, pensando falsamente que esta chave foi combinada $A$. $B$ envia $t_{B}$ para $A$ sem desconfiar de nada.

$$
A \leftarrow t_{C} \leftarrow C \leftarrow t_{B} \leftarrow B
$$

3. $C$ bloqueia $t_{B}$ e envia outro número inteiro no seu lugar, que pode ser $t_{C}$ usado antes.

4. A recebe $t_{C}$ como se fosse $t_{B}$ e faz os cálculos conforme o protocolo, estabelecendo uma chave $K_{A C}$ com $C$, pensando falsamente que esta chave foi combinada com $B$.

5. A partir deste ponto toda mensagem enviada por $A$ criptografada por $K_{A C}$ pode ser decriptografada por $C$, e qualquer mensagem enviada por $B$ criptografada por $K_{B C}$ pode também ser decriptografada por $C$.

$$
A \leftrightarrow K_{A C} \leftrightarrow C \leftrightarrow K_{B C} \leftrightarrow B
$$

\subsubsection{Protocolo Diffie-Hellman modificado}

A modificação feita para evitar o ataque man-in-the-middle consiste da inclusão de um terceiro valor inteiro à chave pública de cada entidade que fica $(p, g, T)$ onde $T=g^{S} \bmod p$.

A entidade $A$ publica previamente a sua chave pública $\left(p_{A}, g_{A}, T_{A}\right)$ e guarda o seu segredo $S_{A}$ tal que $T_{A}=\left(g_{A}\right)^{S_{A}} \bmod p_{A}$. Analogamente $B$ publica $\left(p_{B}, g_{B}, T_{B}\right)$ e guarda $S_{B}$. O protocolo fica como a seguir, quando uma entidade A deseja enviar uma mensagem $\mathrm{x}$ para a entidade $\mathrm{B}$ :

1. $A$ escolhe $S_{A}$ e calcula $\left(g_{B}\right)^{S_{A}} \bmod p_{B}=U_{A}$ e $K_{A B}=\left(T_{B}\right)^{S_{A}} \bmod p_{B}$ e usa $K_{A B}$ para criptografar $x: K_{A B}(x)=y$ e envia $y$ e $U_{A}$ para $B$. 


$$
A \rightarrow y, U_{A} \rightarrow B
$$

2. $B$ calcula $[U A]^{S_{B}} \bmod p_{B}=\left[\left(g_{B}\right)^{S_{A}} \bmod p_{B}\right]_{B}^{S} \bmod p_{B}=K_{A B}$ e usa $K_{A B}$ para decriptografar $y$ e obter $x$.

Note que não há necessidade de um diálogo entre as entidades $A$ e $B$ como no protocolo anterior. 


\section{Capítulo 6}

\section{Algoritmo de Criptografia em Blocos RC6}

O RC6 foi projetado a partir do algoritmo RC5 com o objetivo de atender os requisitos do concurso Advanced Encryption Standard(AES) do instituto americano National Institute of Standards and Technology(NIST). É de autoria de Ronald L. Rivest, M.J.B. Robshaw, R. Sidney e Y.L.Yin [12].

O RC6 faz uso de rotações dependentes dos dados e foi projetado para computadores de 16, 32 ou 64 bits como o RC5, mas utiliza quatro variáveis ao invés de duas e introduziu a operação de multiplicação. Esta operação é utilizada para que as rotações dependentes dos dados dependam de todos os bits da variável ao contrário do RC5 onde é utilizado somente os bits menos significativos. Como o DES e o RC5, o RC6 possui estrutura de uma cifra de Feistel. A simplicidade do RC6 facilita sua análise e implementação em hardware e software.

\subsection{Parâmetros}

Como o RC5, o RC6 é totalmente parametrizado e pode ser especificado de uma maneira precisa como RC6-w/r/b. O $w$ é o número de bits do computador, $r$ é o número de iterações (round) e $b$ é número de bytes da chave. Os parâmetros para o AES são os seguintes: $w=32, r=20$ e chaves com 16, 24 e 32 bytes. Neste texto vamos assumir a notação RC6 para designar a versão com os parâmetros utilizados para o AES.

\subsection{Operações Básicas}

O RC6 $-w / r / b$ utiliza quatro registradores de $w$ bits como operandos e as seguintes operações básicas:

1. $a+b$ adição de inteiros módulo $2^{w}$;

2. $a-b$ subtração de inteiros módulo $2^{w}$;

3. $a \oplus b$ ou-exclusivo bit a bit sobre operandos de $w$ bits; 
4. $a \times b$ multiplicação de inteiros módulo $2^{w}$;

5. $a \lll b$ rotação à esquerda de $a$ de lg $w$ bits menos significativos de $b$.

6. $a \ggg b$ rotação à direita de $a$ de $\lg w$ bits menos significativos de $b$.

A partir desta seção iremos assumir que as operações de adição, subtração e multiplicação de inteiros serão módulo $2^{w}$, caso este não esteja explicitamente indicado.

\subsection{Geração de Subchaves}

O algoritmo é praticamente igual ao do RC5. A única diferença é que para o RC6 mais subchaves são geradas a partir da chave fornecida pelo usuário. O usuário fornece uma chave de $b$ bytes, $0 \leq b \leq 255$. A partir desta chave, $2 r+4$ subchaves, de $w$ bits, são geradas e armazenadas em um vetor $S[0, \ldots, 2 r+3]$. Este vetor é usado tanto para a criptografia como para a decriptografia. As "constantes mágicas" $P_{w}$ e $Q_{w}$ são derivadas das expansões binárias de $e-2$ e $\phi-1$, respectivamente, onde $e$ é a base da função logaritmo natural e $\phi$ é a razão áurea. O algoritmo é apresentado na figura 6.1.

Entrada: Chave de $b$ bytes armazenada previamente em um vetor de $w$ bits $L[0, \ldots, c-1]$

número $r$ de iterações;

Saída: Subchaves armazenadas em variáveis $w$-bits: $S[0], \ldots, S[2 r+3]$;

Procedimento:

$$
\begin{aligned}
& S[0]=P_{w} ; \\
& \text { para } i=1 \text { até } 2 r+3 \text { faça } \\
& S[i]=S[i-1]+Q_{w} \text {; } \\
& A=B=i=j=0 \\
& v=3 \times \max \{c, 2 r+4\} ; \\
& \text { para } s=1 \text { até } v \text { faça }\{ \\
& A=S[i]=(S[i]+A+B) \lll 3 ; \\
& B=L[j]=(L(j]+A+B) \lll(A+B) ; \\
& i=(i+1) \bmod (2 r+4) \text {; } \\
& j=(j+1) \bmod c \text {; } \\
& \text { \} }
\end{aligned}
$$

Figura 6.1: Geração de subchaves do RC6- $w / r / b$ 


\subsection{Criptografia e Decriptografia}

O RC6 utiliza quatro variáveis de $w$ bits $A, B, C$ e $D$. Estas variáveis contém inicialmente o texto legível e no final da criptografia o texto ilegível. Os textos legíveis e ilegíveis são armazenados nas variáveis do seguinte modo: o primeiro byte do texto (i)legível é colocado no byte mais significativo de $A$ e o último byte do texto (i)legível é colocado no byte mais significativo de D. A representação $(A, B, C, D)=(B, C, D, A)$ significa a atribuição paralela dos valores à direita para as variáveis correspondentes à esquerda. Nas figuras 6.2 e 6.4 temos os algoritmos de criptografia e decriptografia com suas representações gráficas nas figuras 6.3 e 6.5 respectivamente.

Entrada: Texto legível armazenado em quatro variáveis de $w$-bits: $A, B, C, D$; número $r$ de iterações;

$2 r+4$ subchaves armazenadas em variáveis de $w$-bits:S[0], $\ldots, S[2 r+3]$;

Saída: Texto ilegível armazenado em $A, B, C, D$;

\section{Procedimento:}

$$
\begin{aligned}
B= & B+S[0] ; \\
D= & D+S[1] ; \\
\text { para } i=1 \text { até } r \text { faça }\{ & \\
& t=(B \times(2 B+1)) \lll l g w ; \\
& u=(D \times(2 D+1)) \lll l g w ; \\
& A=((A \oplus t) \lll u)+S[2 i] ; \\
& C=((C \oplus u) \lll t)+S[2 i+1] ; \\
& (A, B, C, D)=(B, C, D, A) ; \\
\} \quad & \\
A= & A+S[2 r+2] ; \\
C= & C+S[2 r+3]
\end{aligned}
$$

Figura 6.2: Algoritmo de criptografia RC6- $w / r / b$ 


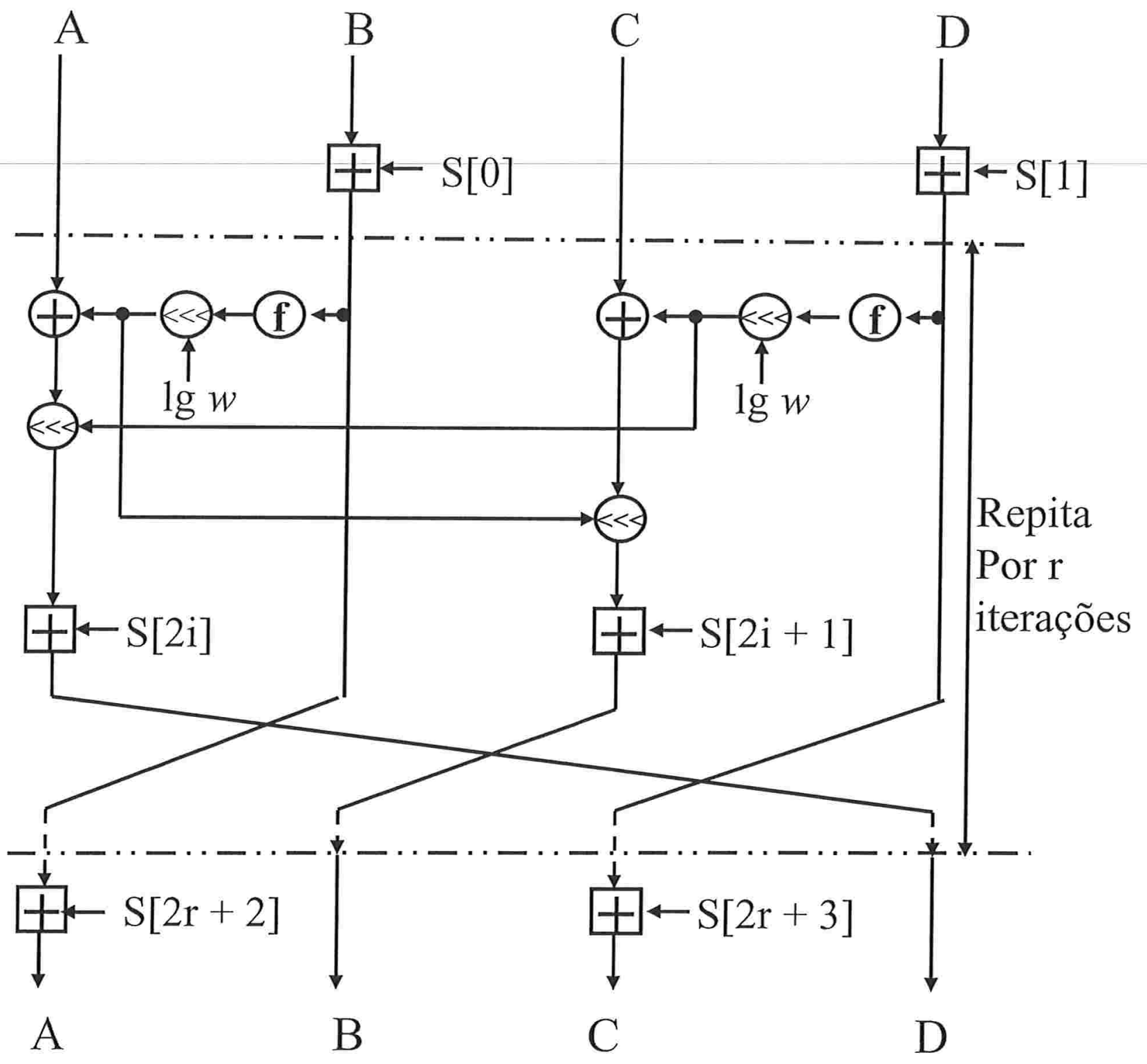

Figura 6.3: Criptografia com o RC6 $-w / r / b$. Onde $f(x)=x(2 x+1)$ 
Entrada: Texto ilegível armazenado em quatro variáveis de $w$-bits: $A, B, C, D$; número $r$ de iterações;

$2 r+4$ subchaves armazenadas em variáveis de $w$-bits: $S[0], \ldots, S[2 r+3]$;

Saída: Texto legível armazenado em $A, B, C, D$;

\section{Procedimento:}

$$
\begin{aligned}
C= & C-S[2 r+3] ; \\
A= & A-S[2 r+2] ; \\
\text { para } i=r \text { até 1faça }\{ & \\
& (A, B, C, D)=(B, C, D, A) ; \\
& u=(D \times(2 D+1)) \lll l g w ; \\
& t=(B \times(2 B+1)) \lll l g w ; \\
& C=((C-S[2 i+1]) \ggg t) \oplus u ; \\
& A=((A-S[2 i]) \ggg u) \oplus t ; \\
\} \quad & \\
D= & D-S[1] ; \\
B= & B-S[0]
\end{aligned}
$$

Figura 6.4: Algoritmo de decriptografia RC6- $w / r / b$ 


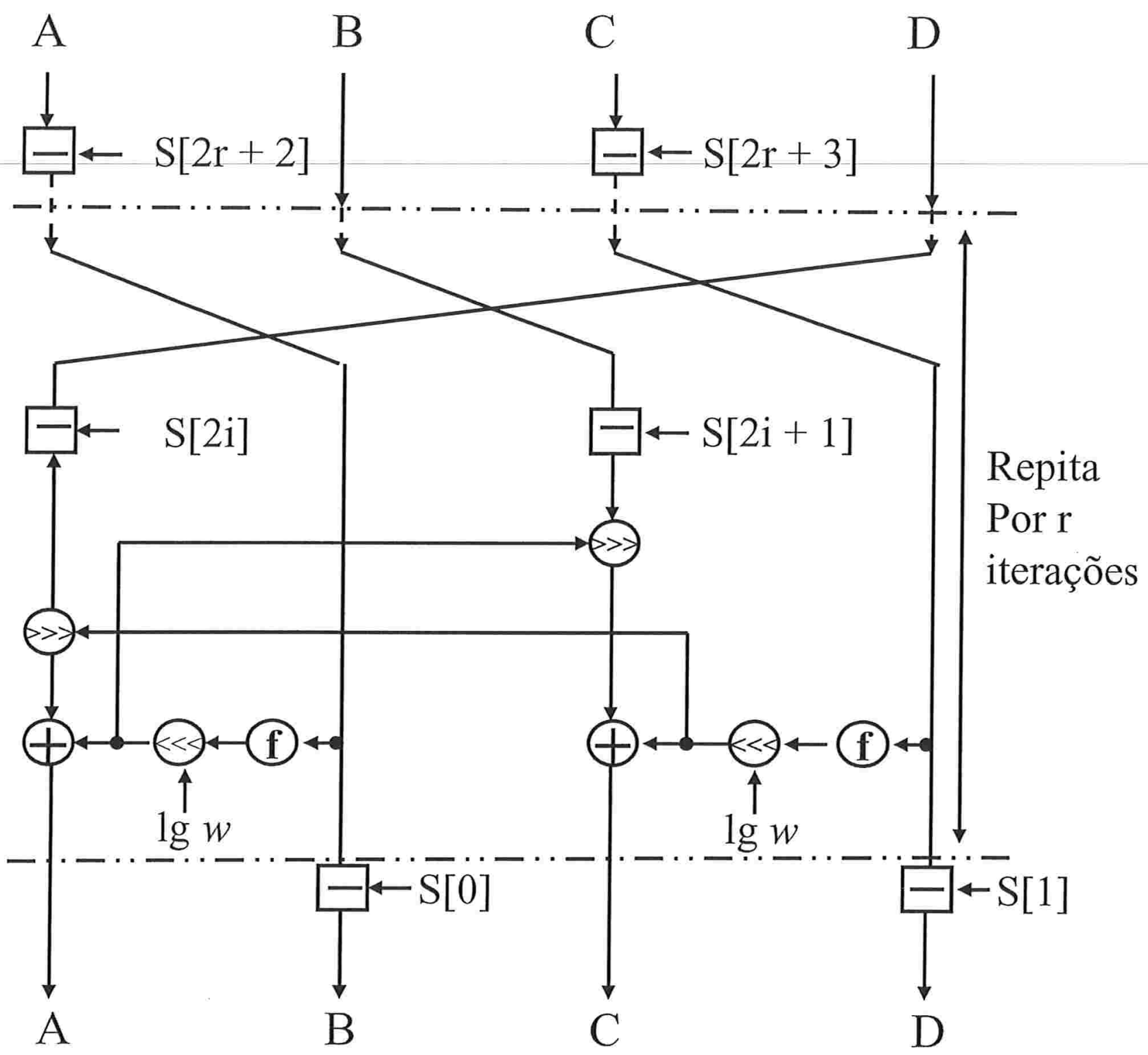

Figura 6.5: Decriptografia com o RC6 $-w / r / b$. Onde $f(x)=x(2 x+1)$ 


\subsection{Segurança do RC6}

Nesta seção discutiremos a segurança do RC6 com base no relatório feito com a colaboração dos próprios autores do algoritmo [3]. A análise foi baseada nos dois ataques mais efetivos contra algoritmos de criptografia em blocos: criptanálise diferencial e criptanálise Linear. Destes dois ataques vamos nos concentrar na criptanálise diferencial que será detalhada no capítulo 7, pois introduzimos uma modificação com o objetivo de fortalecer o algoritmo contra este tipo de ataque. Esta modificação será descrita no capítulo 8.

\subsubsection{Ataques contra o RC6}

\section{Força bruta}

Os autores do algoritmo supõe que o melhor ataque ao RC6 é a busca exaustiva dos bytes da chave [12]. Este tipo de ataque pode ser utilizado em qualquer algoritmo em bloco com chave secreta e só pode ser contido através da utilização de chaves longas.

O esforço requerido para busca dos $b$ bytes da chave ou do vetor expandido da chave $S[0, \ldots, 43]$ (20 iterações) é $\min \left\{2^{8 b}, 2^{1408}\right\}$ operações. Uma quantidade de memória superior a $2^{700}$ bytes e por volta de $2^{704}$ pré-computações. Para o tamanho de chaves especificado pelo AES um ataque utilizando a força bruta parece impraticável [3].

\section{Ataques analíticos}

A tabela 6.1 contém um resumo da análise feita em [3]. Os valores que estão marcados por um quadro indicam os valores acima de $2^{128}$, que é número máximo de textos legíveis possíveis. Com base nesta tabela é possível concluir que o RC6 com 20 iterações está seguro contra ataques por criptanálise diferencial e linear.

\begin{tabular}{||c||ccccc||}
\hline \multicolumn{1}{|c||}{} & \multicolumn{5}{c||}{ Número de iterações } \\
\hline Ataque & 8 & 12 & 16 & 20 & 24 \\
\hline Criptanálise Diferencial & $2^{56}$ & $2^{117}$ & $2^{190}$ & $2^{238}$ & {$\left[2^{299}\right.$} \\
\hline Criptanálise Linear & $2^{47}$ & $2^{83}$ & $2^{119}$ & $2^{155}$ & {$\left[2^{191}\right.$} \\
\hline
\end{tabular}

Tabela 6.1: Estimativa de textos legíveis para atacar o RC6 [3] 


\section{Capítulo 7}

\section{Criptanálise Diferencial do RC6}

Criptanálise diferencial é um ataque por texto escolhido em algoritmos em blocos iterados. Este método analisa o efeito de diferenças particulares em pares de textos legíveis sobre as diferenças do texto ilegível resultante. Em função da escolha dos pares de texto legível com uma diferença particular é possível uma previsão dos valores de entrada da última iteração com certa probabilidade. A definição de "diferença" depende do algoritmo sendo atacado. O objetivo é que a diferença prevista entre os pares de entrada da última iteração possa ser utilizado junto com a diferença do par de texto ilegível, que é conhecido, para obtenção de informação sobre a subchave utilizada na última iteração. Este ataque foi desenvolvido por Biham e Shamir em 1990, detalhes podem ser encontrados em [1].

Vale notar que a probabilidade que um par de textos escolhidos forneça uma determinada diferença após a iteração $(r-1)$ decresce conforme $r$ cresce. Portanto, ataques em versões reduzidas, quanto ao número de iterações, podem ser efetivas, mas não se tivermos um número de iterações do algoritmo completo.

A escolha ótima da diferença entre os pares de texto legível é calculada pela avaliação da característica, esta especifica as diferenças esperadas para cada iteração da cifra. Uma característica tem uma probabilidade associada, que é baseada na diferença da última iteração da característica, em função da diferença dos pares de entrada[3].

Lay, Massey e Murphy [9] introduziram a idéia de diferencial, que é uma versão mais ampla de característica, onde, apenas as diferenças de entrada e saída são fixadas enquanto a diferença das iterações intermediárias não são consideradas.

Um fato importante é a relação do RC6 com o RC5. O RC5 está disponível desde dezembro de 1994 e nenhum ataque efetivo utilizando técnicas de criptanálise diferencial foi relatada.

Os lemas apresentados neste capítulo foram retirados de [3] onde também se encontram as respectivas demonstrações.

\subsection{Criptanálise diferencial do RC5}

Análises do RC5 mostram que a melhor estratégia para o criptanalista é o uso de diferenças que não afetam a quantidade de rotação. A partir deste fato, a estratégia definida para criptanálise do RC6 utiliza diferenças que não causam rotações diferentes para um determinado par. 
Outro fato relevante é a vantagem obtida em se manter o peso de Hamming tão baixo quanto possível das diferenças intermediárias. Desta forma, temos um melhor controle da evolução da característica ou diferencial.

\subsection{A Função quadrática}

A função quadrática é a principal inovação introduzida na evolução do RC5 para o RC6. Seu objetivo é tornar a rotação dependente dos dados, que é derivada da saída da função quadrática, dependente de todos os bits da variável de entrada. Este fato deve frustrar os ataques diferenciais que se aplicam ao RC5.

A medida de diferença utilizada para análise da função quadrática será a subtração de inteiros, pelo fato desta função utilizar as operações de adição e multiplicação de inteiros. Também será apresentada uma comparação com a utilização da operação ou-exclusivo. Os detalhes da função quadrática podem ser encontrados em [3].

No texto [3] o termo característica $\delta_{x}=\delta_{y}$, quando não acompanhado de adjetivo, tem o mesmo significado de $\delta_{x} \rightarrow \delta_{y}, \delta_{x}$ causa $\delta_{y}$, definido em [1]. Portanto, adotamos a notação do texto [3] para facilitar a análise e comparação.

\subsubsection{Propriedades básicas}

Lema 7.2.1. Seja $f(x)=x(a x+b) \bmod 2^{w}$ onde a é par e b e ímpar. Então $f(x)$ é uma bijeção de $\{0,1\}^{w}$ em $\{0,1\}^{w}$.

Lema 7.2.2. Para entradas $x_{1}$ e $x_{2}$, seja $y_{1}=f\left(x_{1}\right)$ e $y_{2}=f\left(x_{2}\right)$. Definindo-se $\delta_{x}=$ $x_{2}-x_{1} e \delta_{y}=y_{2}-y_{1}$. Então

$$
\delta_{y}=\left(4 x_{1} \delta_{x}+\delta_{x}+\delta_{x}^{2}\right) \bmod \left(2^{32}\right)
$$

O lema seguinte não é utilizado diretamente, mas justifica a utilização dos bits mais significativos pela função de rotação dependente dos dados.

Lema 7.2.3. Dada uma seqüência $x_{1}$ escolhida aleatoriamente de uma distribuição uniforme, seja $g_{i, j}$ a probabilidade de uma alteração no bit $i$ de $x_{1}$ irá alterar o bit $j$ de $y_{1}=f\left(x_{1}\right)$. Então

$$
\begin{gathered}
g_{i, j}=\left\{\begin{array}{l}
0 \text { se } j<i, \\
1 \quad \text { se } j=i, \\
1 \quad \text { se } j=1 \text { e } i=0, \text { e }
\end{array}\right. \\
g_{i, j} \in[1 / 4,3 / 4] \text { paraj }>i \geq 1 \text { ouj } \leq \text { e } i=0 .
\end{gathered}
$$

Para o último caso, $g_{i, j}$ esta próximo de $3 / 4$ se $j=2 i+2$, e para a maioria dos outros pares $i, j, g_{i, j}$ esta próximo de $1 / 2$

\subsection{Subtração de inteiros como medida de diferença}

Nesta seção serão apresentados os resultados de características da função quadrática da forma $\delta_{x}=\delta_{y}[3]$. Estas características serão chamadas características estáticas para função quadrática. 
Lema 7.3.1. Se $\delta_{x}$ é ímpar então a característica $\delta_{x}=\delta_{y}$ vale com probabilidade zero.

Lema 7.3.2. Se $\delta_{x}=v 2^{i}$ para algum inteiro $v$ ímpar $e 1 \leq i \leq 30$, então a característica $\delta_{x}=\delta_{y}$ vale com probabilidade $2^{i-30}$. Se $\delta_{x}=2^{31}$, então a característica pela função quadrática $\delta_{x}=\delta_{y}$ vale com probabilidade um.

\subsection{Ou-exclusivo como medida de diferença}

Nesta seção será considerada a operação ou-exclusivo como medida de diferença. Após a análise será possível uma comparação com a medida de diferença da seção 7.3. Vamos utilizar a seguinte notação:

$$
\begin{aligned}
& \delta_{x}^{\oplus}=x_{2} \oplus x_{1}, \quad e \\
& \delta_{y}^{\oplus}=y_{2} \oplus y_{1} .
\end{aligned}
$$

Lema 7.4.1. Seja $p_{i}$ a probabilidade da característica $\delta_{x}=\delta_{y}=2^{i}$. Então

$$
\begin{gathered}
p_{i}= \begin{cases}1 & \text { se } i=31 \\
2^{i-30} & \text { se } 15 \leq i \leq 20, \\
0 & \text { se } 0 \leq i \leq 14,\end{cases} \\
p_{i} \approx 2^{i-31} \text { se } 21 \leq i \leq 30 .
\end{gathered}
$$

\subsection{Comparando subtração de inteiros e ou-exclusivo}

Com os resultados das seções anteriores podemos comparar as medidas de diferença. Esta comparação irá utilizar as probabilidades apresentadas nos lemas 7.3.2 e 7.4.1 e mostradas na tabela $7.1 \mathrm{~A}$ tabela nos mostra que as probabilidades são maiores para as características

\begin{tabular}{||c||c||c||}
\hline Posição do bit $i$ & probabilidade $\delta_{x}=\delta_{y}=2^{i}$ & probabilidade $\delta_{x}^{\oplus}=\delta_{y}^{\oplus}=2^{i}$ \\
\hline \hline 31 & 1 & 1 \\
\hline $21 \leq i \leq 30$ & $2^{i-30}$ & $\approx 2^{i-31}$ \\
\hline $15 \leq i \leq 20$ & $2^{i-30}$ & $2^{i-30}$ \\
\hline $1 \leq i \leq 14$ & $2^{i-30}$ & 0 \\
\hline 0 & 0 & 0 \\
\hline
\end{tabular}

Tabela 7.1: Probabilidades para características estáticas para a função quadrática. [3]

que utilizam a subtração como medida de diferença. E o mais importante, para valores de $i \leq 14$ só podemos utilizar a subtração, uma vez que as diferenças com ou-exclusivo tem valor zero.

Agora vamos verificar como se comportam as outras operações do RC6 em relação a subtração de inteiros. A proposta no relatório [3] é o estudo da função composta $w=z \oplus f(x)$ como um único componente.

Para dois conjuntos de entrada $x_{1}, z_{1}$ e $x_{2}, z_{2}$ vamos definir $w_{1}=z_{1} \oplus f\left(x_{1}\right)$ e $w_{2}=$ $z_{2} \oplus f\left(x_{2}\right)$ e suas diferenças $\delta_{x}=x_{2}-x_{1}, \delta_{z}=z_{2}-z_{1}$ e $\delta_{w}=w_{2}-w_{1}$. 
Lema 7.5.1. Seja $p_{i}$ a probabilidade da característica $\left(\delta_{x}, \delta_{z}\right) \rightarrow \delta_{w}$ onde $\left(\delta_{x}, \delta_{z}\right)=\left(2^{i}, 0\right)$ e $\delta_{w}=2^{i}$. Do mesmo modo, seja $q_{i}$ a probabilidade da característica $\left(\delta_{x}, \delta_{z}\right) \rightarrow \delta_{w}$ onde $\left(\delta_{x}, \delta_{z}\right)=\left(2^{i}, 2^{i}\right)$ e $\delta_{w}=0$. Então sempre teremos $p_{i}=q_{i} e$

$$
q_{i}=p_{i}= \begin{cases}2^{i-31} & \text { se } 15 \leq i \leq 31 \\ x \in\left[2^{i-35}, 2^{i-30}\right] & \text { se } 0 \leq i \leq 14\end{cases}
$$

O lema 7.5.1 demonstra que, apesar da não uniformidade da característica, a subtração de inteiros é melhor que o ou-exclusivo para a criptanálise do RC6.

\subsection{Características e Diferenciais Iterativos para o RC6}

Uma característica é iterativa quando a saída da última iteração é igual a entrada da primeira. Desta forma pode-se concatenar uma característica iterativa a ela mesma um número arbitrário de vezes para obtenção de características com um número arbitrário de iterações.

A partir desta seção vamos utilizar a seguinte notação:

$e_{i}$-Variável de 32 bits com o bit zero em todas posições, exceto na posição $i$. Em termos de números inteiros temos: $e_{i}=2^{i}$;

$\Delta$-Diferença genérica pela aplicação de uma iteração do RC6;

$\rho$-Probabilidade que uma diferença $\Delta$ não se altere através da rotação dependente dos dados.

$\downarrow$-Ação de uma iteração de criptografia.

Em geral vamos assumir ataques ao RC6 de $r$ iterações, onde diferenciais de $(r-2)$ iterações são necessários e que o número de pares de textos legíveis escolhidos necessários é inversamente proporcional à probabilidade da característica ou diferencial.

Baseado no lema 7.5.1 podemos construir as seguintes características de um bit para uma iteração do RC6:

$$
\begin{array}{ccccccccc}
0 & 0 & e_{t+5} & e_{t} & \text { e } & 0 & 0 & 0 & e_{t} \\
& & \downarrow & & & & & \downarrow & \\
0 & 0 & e_{t} & 0 & & 0 & e_{s} & e_{t} & 0
\end{array}
$$

A característica à esquerda vale com probabilidade $q_{t}$ e à direita vale com probabilidade $\rho \times p_{t}$ onde $q_{t}$ e $p_{t}$ são dadas pelo lema 7.5.1.

Utilizando estas duas características podemos montar a característica da tabela 7.2. As restrições às variáveis devido a rotação constante são $0 \leq t, s, v \leq 26$ e $15 \leq u \leq 26$. Qualquer característica satisfazendo estas restrições vale com probabilidade

$$
\rho^{6} \times\left(q_{t} \times p_{s} \times p_{v} \times p_{u} \times q_{u-5} \times q_{u-10}\right) .
$$

Com base na característica de seis iterações vamos avaliar o diferencial de seis iterações. Fixando-se um valor para $t$, temos 27 valores possíveis para $s$ e $t$. Para maximizar a 


\begin{tabular}{|c|c|c|c|c|c|c|c|}
\hline \multicolumn{4}{|c|}{ Geral } & \multicolumn{4}{|c|}{ Escolha específica } \\
\hline$e_{t+5}$ & $\begin{array}{r}e_{t} \\
\downarrow\end{array}$ & 0 & 0 & $e_{16}$ & $e_{11}$ & 0 & 0 \\
\hline$e_{t}$ & $\begin{array}{l}0 \\
\downarrow\end{array}$ & 0 & 0 & $e_{11}$ & 0 & 0 & 0 \\
\hline 0 & $\begin{array}{l}0 \\
\downarrow\end{array}$ & 0 & $e_{s}$ & 0 & 0 & 0 & $e_{26}$ \\
\hline 0 & $\begin{array}{r}e_{u} \\
\downarrow\end{array}$ & $e_{s}$ & 0 & 0 & & $e_{26}$ & 0 \\
\hline$e_{u}$ & $\begin{array}{c}e_{u-5} \\
\downarrow\end{array}$ & 0 & $e_{v}$ & $e_{26}$ & & 0 & $e_{26}$ \\
\hline$e_{u-5}$ & $\begin{array}{c}e_{u-10} \\
\downarrow\end{array}$ & $e_{v}$ & 0 & $e_{21}$ & $e_{16}$ & $e_{26}$ & 0 \\
\hline$e_{u-10}$ & $e_{u-15}$ & 0 & 0 & $e_{16}$ & $e_{11}$ & 0 & 0 \\
\hline
\end{tabular}

Tabela 7.2: Característica iterativa genérica de seis iterações para o RC6 [3].

probabilidade do diferencial façamos $t=11$ e $u-15=11 \mathrm{com} s$ e $v$ livres. Desta forma, podemos calcular a probabilidade do diferencial de seis iterações, utilizando os valores do lema 7.5.1, como

$$
\begin{aligned}
& \rho^{6} \times q_{11} \times\left(\sum_{i=0}^{26} p_{i}\right)^{2} \times p_{26} \times q_{21} \times q_{16} \\
\approx & 2^{-30} \times 2^{-23} \times\left(2^{-4}\right)^{2} \times 2^{-5} \times 2^{-10} \times 2^{-15} \\
= & 2^{-91} .
\end{aligned}
$$

O diferencial iterativo de seis rounds será indicado por $I_{6}$.

\subsection{Diferenciais não iterativos para o RC6}

Nesta seção vamos refinar nossa análise através da construção de diferenciais não iterativos com probabilidade melhor do que o iterativo. Estes diferenciais foram construídos sob medida para serem concatenados ao diferencial $I_{6}$ e serão indicados como $E_{2}, E_{4} E_{6}$ e $E_{6}^{\prime}$ para serem concatenados no final, e $B_{2}, B_{4}$ e $B_{6}$ para serem concatenados no início. Estes diferenciais podem ser vistos nas tabelas 7.3 e 7.4 .

Com a combinação destes diferenciais podemos construir ataques mais eficientes. Na tabela 7.5 temos uma comparação dos ataques utilizando as diversas características apresentadas. 


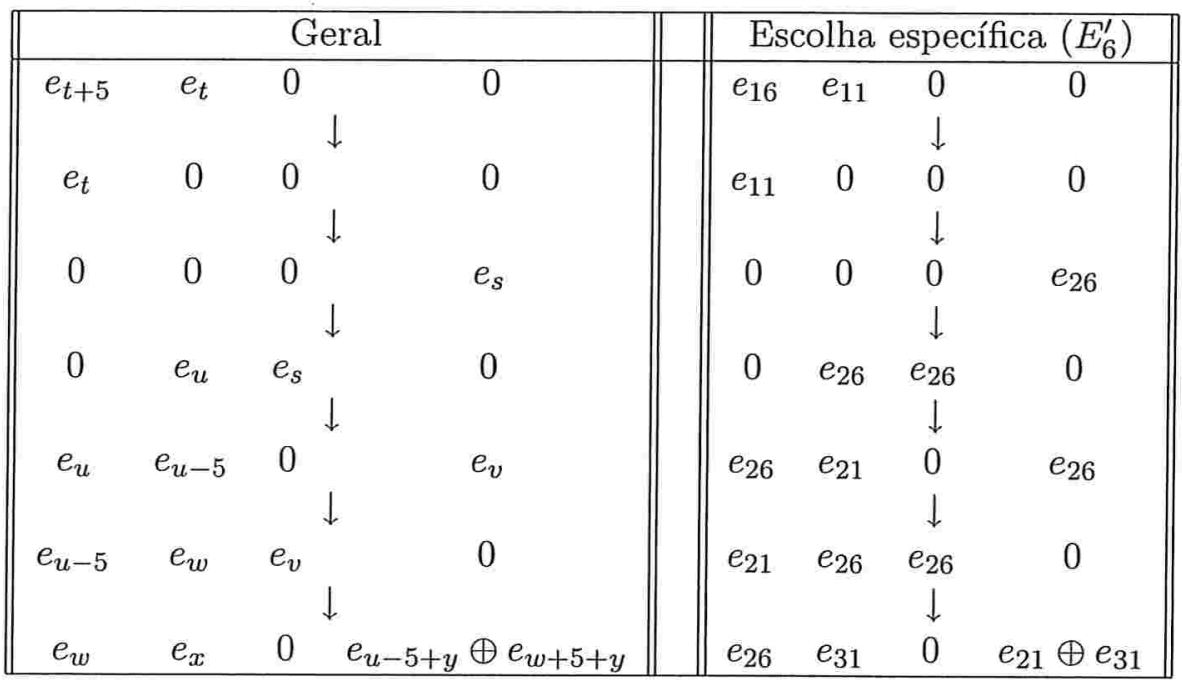

Tabela 7.3: Característica não iterativa genérica de seis iterações para o RC6 [3]. 


\begin{tabular}{|c|c|c|c|c|c|c|}
\hline \multicolumn{3}{|c|}{$B_{2}\left(2^{-40}\right)$} & \multicolumn{4}{|c|}{$E_{2}\left(2^{-23}\right)$} \\
\hline$e_{26}$ & $e_{21}{ }^{0}$ & $e_{26}$ & $e_{16}$ & & $\begin{array}{l}0 \\
\downarrow\end{array}$ & 0 \\
\hline$e_{21}$ & $e_{16} e_{26}$ & 0 & $e_{26}$ & 0 & $\begin{array}{l}0 \\
\downarrow\end{array}$ & 0 \\
\hline$e_{16}$ & $\begin{array}{ll}e_{11} & 0\end{array}$ & $e_{s}$ & 0 & 0 & 0 & $e_{26}$ \\
\hline
\end{tabular}

\begin{tabular}{|c|c|c|c|c|c|c|}
\hline \multicolumn{3}{|c|}{$B_{4}\left(2^{-63}\right)$} & \multicolumn{4}{|c|}{$E_{4}\left(2^{-41}\right)$} \\
\hline 0 & $\begin{array}{lll}0 & & 0 \\
& \downarrow\end{array}$ & $e_{26}$ & $e_{16}$ & $e_{11}$ & $\begin{array}{l}0 \\
\downarrow\end{array}$ & 0 \\
\hline 0 & $e_{u} e^{e_{26}}$ & 0 & $e_{26}$ & 0 & $\begin{array}{l}0 \\
\downarrow\end{array}$ & 0 \\
\hline$e_{u}$ & $e_{21} \quad 0$ & $e_{v}$ & 0 & 0 & $\begin{array}{l}0 \\
\downarrow\end{array}$ & $e_{s}$ \\
\hline$e_{21}$ & $e_{16} e_{v}$ & 0 & 0 & $e_{26}$ & $e_{s}$ & 0 \\
\hline$e_{16}$ & $\begin{array}{ll}e_{11} & 0\end{array}$ & 0 & $e_{26}$ & $e_{21}$ & 0 & $e_{26}$ \\
\hline
\end{tabular}

\begin{tabular}{|c|c|c|c|c|c|c|}
\hline \multicolumn{3}{|c|}{$B_{6}\left(2^{-76}\right)$} & \multicolumn{4}{|c|}{$E_{6}\left(2^{-71}\right)$} \\
\hline$e_{31}$ & $e_{26}{ }^{e^{\prime}} \quad 0$ & 0 & $e_{16}$ & $e_{11}$ & $\begin{array}{l}0 \\
\downarrow\end{array}$ & 0 \\
\hline$e_{26}$ & $\begin{array}{ll}0 & \\
& \\
\downarrow & \end{array}$ & 0 & $e_{11}$ & 0 & $\begin{array}{l}0 \\
\downarrow\end{array}$ & 0 \\
\hline 0 & $\begin{array}{ll}0 & 0 \\
& \downarrow\end{array}$ & $e_{s}$ & 0 & 0 & $\begin{array}{l}0 \\
\downarrow\end{array}$ & $e_{s}$ \\
\hline 0 & $e_{\downarrow}^{e_{26}} e_{s}$ & 0 & 0 & $e_{26}$ & $e_{s}$ & 0 \\
\hline$e_{26}$ & $e_{21}{ }^{0}$ & $e_{v}$ & $e_{26}$ & $e_{21}$ & $\begin{array}{l}0 \\
\downarrow\end{array}$ & $e_{v}$ \\
\hline$e_{21}$ & $e_{16}^{e_{16}} e_{v}$ & 0 & $e_{21}$ & $e_{26}$ & $e_{v}$ & 0 \\
\hline$e_{16}$ & $e_{11} \quad 0$ & 0 & $e_{26}$ & $e_{31}$ & 0 & $e_{21} \oplus e_{31}$ \\
\hline
\end{tabular}

Tabela 7.4: Característica não iterativa genérica de duas, quatro e seis iterações para o RC6.Entre parênteses estão as probabilidades associadas aos diferencias[3]. 


\begin{tabular}{||c||c|c|c|c|c||}
\hline \multicolumn{1}{||c||}{} & \multicolumn{5}{c||}{ Número de iterações } \\
\hline $\begin{array}{c}\text { Variante } \\
\text { RC6 } \\
\text { Característica Iterativa }\end{array}$ & $2^{93}$ & $2^{151}$ & $2^{214}$ & $2^{279}$ & $2^{337}$ \\
\hline $\begin{array}{c}\text { RC6 } \\
\text { Diferencial Iterativo }\end{array}$ & $2^{91}$ & $2^{147}$ & $2^{210}$ & $2^{273}$ & $2^{329}$ \\
\hline $\begin{array}{c}\text { RC6 } \\
\text { Diferenciais } \\
\text { Ajustados }\end{array}$ & $2^{56}$ & $2^{117}$ & $2^{190}$ & $2^{238}$ & $2^{299}$ \\
$E_{6}^{\prime}$ & $B_{6} \mid E_{4}$ & $\begin{array}{c}B_{6} \mid I_{6} \\
\mid E_{2}\end{array}$ & $\begin{array}{c}B_{6} \mid I_{6} \\
\mid E_{6}\end{array}$ & $\begin{array}{c}B_{6} \mid I_{6} \\
\left|I_{6}\right| E_{4}\end{array}$ \\
\hline
\end{tabular}

Tabela 7.5: Estimativa de textos legíveis para atacar o RC6 [3] 


\section{Capítulo 8}

\section{Algoritmo RC6 modificado}

Neste capítulo, apresentamos uma versão modificada do RC6, que tem por objetivo fortalecê -lo contra a criptanálise diferencial. Esta modificação foi baseada na introdução da função de troca utilizada para fortalecer o algoritmo FEAL contra criptanálise diferencial proposta por Terada, Pinheiro e Koyama em [13].

O RC6, segundo seus autores [3], é seguro contra o ataque por criptanálise diferencial na versão apresentada ao AES. Portanto, seria desnecessário o fortalecimento do algoritmo contra este tipo de ataque. Mas, além do estudo teórico, esta alteração poderia ser avaliada para utilização em uma versão com um número reduzido de iterações, mais eficiente e tão segura quanto a versão apresentada para ao AES.

\subsection{RC6T: O RC6 com trocas}

O número de pares escolhidos necessários para a criptanálise diferencial é inversamente proporcional à probabilidade do diferencial[9]. Uma maneira de aumentarmos a resistência de um algoritmo seria pela diminuição da probabilidade dos diferenciais utilizados para atacá-lo. Isto é conseguido pela introdução da função de troca nas duas metades do bloco de entrada do RC6.

Definição 8.1.1. Seja $X$ uma seqüência de 32 bits. Então $X_{E}$ é a seqüência formada pelos 16 bits mais significativos de $X$ e $X_{D}$ é a seqüência formada pelos 16 bits menos significativos de $X$. Se $X_{E}=X_{D}$ então diremos que $X$ é simétrica.

Definição 8.1.2. Seja $X=\left(X_{E} ; X_{D}\right)$ uma seqüência de 32 bits. Definimos a função de troca $T$ por:

$$
T(X)= \begin{cases}\left(X_{E} ; X_{D}\right), & \text { se o número de bits iguais a } 1 \text { em } X \text { é par } \\ \left(X_{D} ; X_{E}\right), & \text { caso contrário }\end{cases}
$$

Definição 8.1.3. Seja $I$ um conjunto qualquer e $g$ uma função em $I$. Dizemos que $g$ é uma involução se para todo $i \in I, g(g(i))=i$.

Lema 8.1.1. Cada iteração do RC6T é inversível.

Demonstração. Sejam $\left(A_{i}, B_{i}, C_{i}, D_{i}\right)$ e $\left(a_{i}, b_{i}, c_{i}, d_{i}\right)$, os blocos de entrada e saída, respectivamente, da $i$-ésima iteração do RC6 ou RC6T. Vamos definir as seguintes funções que 
representam uma iteração de criptografia e decriptografia para o RC6 e RC6T, onde os quatro primeiros parâmetros são o bloco de entrada, os quatro parâmetros seguintes são o bloco de saída e os dois últimos são as subchaves utilizadas na $i$-ésima iteração:

- $\operatorname{CRC6}\left(A_{i}, B_{i}, C_{i}, D_{i}, a_{i}, b_{i}, c_{i}, d_{i}, S[i], S[i+1]\right)$ iteração de criptografia RC6

- DCRC6 $\left(a_{i}, b_{i}, c_{i}, d_{i}, A_{i}, B_{i}, C_{i}, D_{i}, S[i], S[i+1]\right.$ iteração de decriptografia RC6

- $\operatorname{CRC6T}\left(A_{i}, B_{i}, C_{i}, D_{i}, a_{i}, b_{i}, c_{i}, d_{i}, S[i], S[i+1]\right)\{$ CRC6 $\left.\left(A_{i}, T\left(B_{i}\right), C_{i}, T\left(D_{i}\right), a_{i}, b_{i}, c_{i}, d_{i}, S[i], S[i+1]\right)\right\}$ iteração de criptografia RC6T

- DCRC6T $\left(a_{i}, b_{i}, c_{i}, d_{i}, A_{i}, B_{i}, C_{i}, D_{i}, S[i], S[i+1]\right)\{$ $\left.\operatorname{DCRC} 6\left(a_{i}, b_{i}, c_{i}, d_{i}, A_{i}, T\left(T\left(B_{i}\right)\right), C_{i}, T\left(T\left(D_{i}\right)\right), S[i], S[i+1]\right)\right\}$ iteração de decriptografia RC6T

As funções $C R C 6 T$ DCRC6T são equivalentes a alteração com a introdução da função de troca. Na função $C R C 6 T$ é utilizada a operação de troca nas variáveis $B$ e $D$, então é chamada a função $C R C 6$. Na decriptografia as quatro variáveis são passadas para a função $D R C 6 T$ que chama a $D R C 6$ e aplica a função de troca nas variáveis retornadas $B$ e $D$, como a função de troca é uma involução e cada iteração do RC6 é inversível temos:

$$
T\left(T\left(B_{i}\right)\right)=B_{i}
$$

e

$$
T\left(T\left(D_{i}\right)\right)=D_{i}
$$

Logo, $\left(A_{i}, B_{i}, C_{i}, D_{i}\right)$ pode ser obtido a partir de $\left(a_{i}, b_{i}, c_{i}, d_{i}\right)$ e cada iteração é inversível.

Lema 8.1.2. O RC6T é inversível.

Demonstração. O RC6T só difere do RC6 dentro de cada iteração. Como o RC6 é inversível e, pelo lema 8.1.1, cada iteração do RC6T é inversível segue que o RC6T é inversível.

Lema 8.1.3. O RC6T não altera a propriedade da função quadrática do RC6 enunciada no lema 7.2.3

Demonstração. A única diferença entre o RC6 e o RC6T é a função de troca, e esta só altera a posição dos bits e não seus valores, é um caso particular de permutação. Então continuam válidas as premissas e o lema para o RC6T.

Deste modo, o RC6T é simétrico, mantém as propriedades do RC6 e é implementável de maneira eficiente em software como veremos na seção 10.2. Nas figuras 8.1 e 8.3 temos os algoritmos de criptografia e decriptografia com suas representações gráficas nas figuras 8.2 e 8.4 respectivamente. 
Entrada: Texto legível armazenado em quatro variáveis de $w$-bits: $A, B, C, D$; número $r$ de iterações;

$2 r+4$ subchaves armazenadas em variáveis de $w$-bits:S[0], $\ldots, S[2 r+3]$;

Saída: Texto ilegível armazenado em $A, B, C, D$;

\section{Procedimento:}

$$
\begin{aligned}
B= & B+S[0] ; \\
D= & D+S[1] ; \\
\text { para } i=1 \text { até } r \text { faça }\{ & \\
& B=\text { Troca }(B) ; \\
& D=\text { Troca }(D) ; \\
& t=(B \times(2 B+1)) \lll l g w ; \\
& u=(D \times(2 D+1)) \lll l g w ; \\
& A=((A \oplus t) \lll u)+S[2 i] ; \\
& C=((C \oplus u) \lll t)+S[2 i+1] ; \\
& (A, B, C, D)=(B, C, D, A) ; \\
\} \quad & \\
A= & A+S[2 r+2] ; \\
C= & C+S[2 r+3]
\end{aligned}
$$

Figura 8.1: Algoritmo de criptografia RC6T- $w / r / b$ 


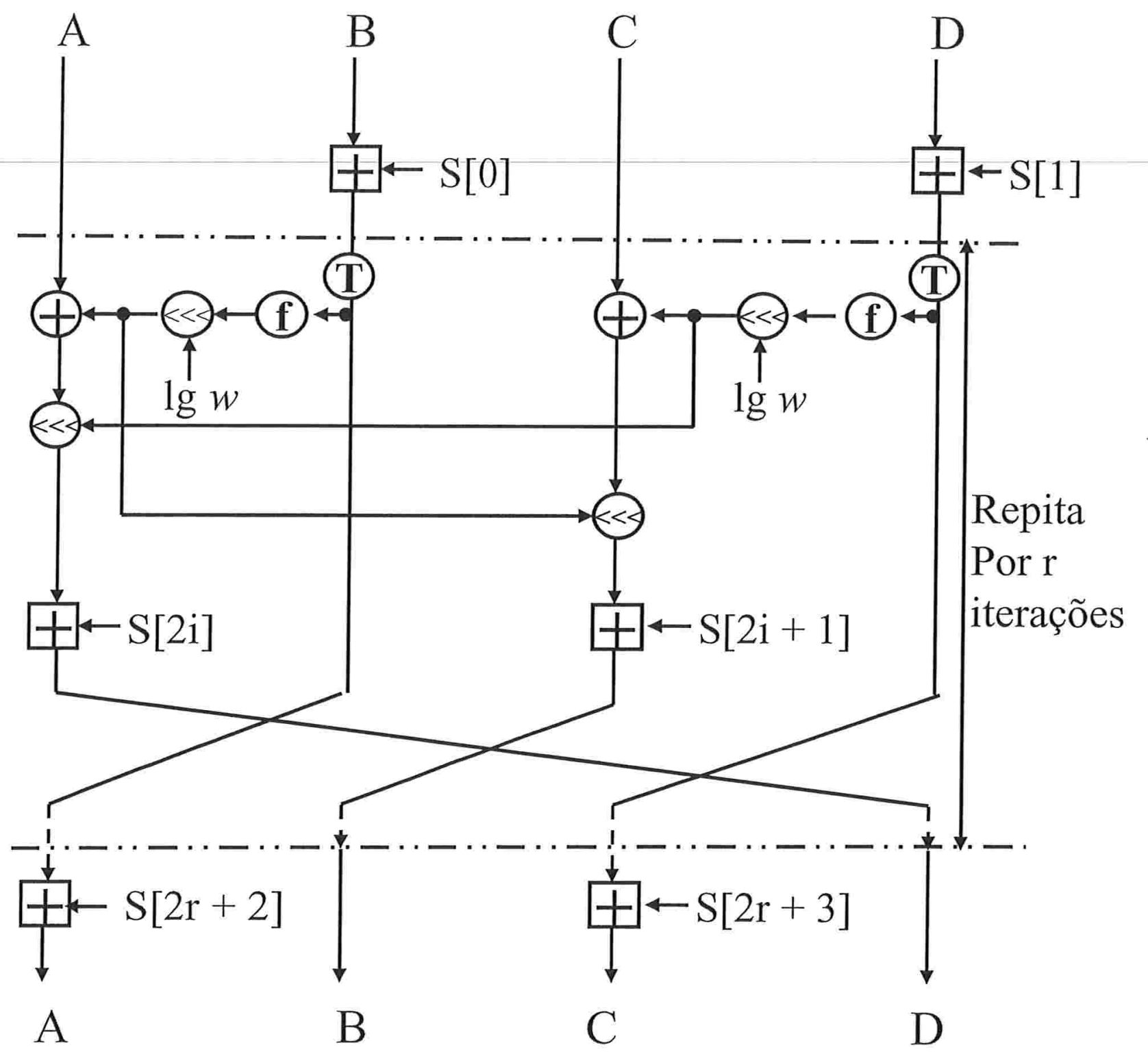

Figura 8.2: Criptografia com o RC6T $-w / r / b$. Onde $f(x)=x(2 x+1)$ e $T$ função de troca 
Entrada: Texto ilegível armazenado em quatro variáveis de $w$-bits: $A, B, C, D$; número $r$ de iterações;

$2 r+4$ subchaves armazenadas em variáveis de $w$-bits: $S[0], \ldots, S[2 r+3]$;

Saída: Texto legível armazenado em $A, B, C, D$;

Procedimento:

$$
\begin{aligned}
C= & C-S[2 r+3] ; \\
A= & A-S[2 r+2] ; \\
\text { para } i=r \text { até 1faça }\{ & \\
& (A, B, C, D)=(B, C, D, A) ; \\
& u=(D \times(2 D+1)) \lll l g w ; \\
& t=(B \times(2 B+1)) \lll l g w ; \\
& C=((C-S[2 i+1]) \ggg t) \oplus u ; \\
& A=((A-S[2 i]) \ggg u) \oplus t ; \\
& B=\operatorname{Troca}(B) ; \\
& D=\operatorname{Troca}(D) ; \\
\} \quad & \\
D= & D-S[1] ; \\
B= & B-S[0]
\end{aligned}
$$

Figura 8.3: Algoritmo de decriptografia RC6T- $w / r / b$ 


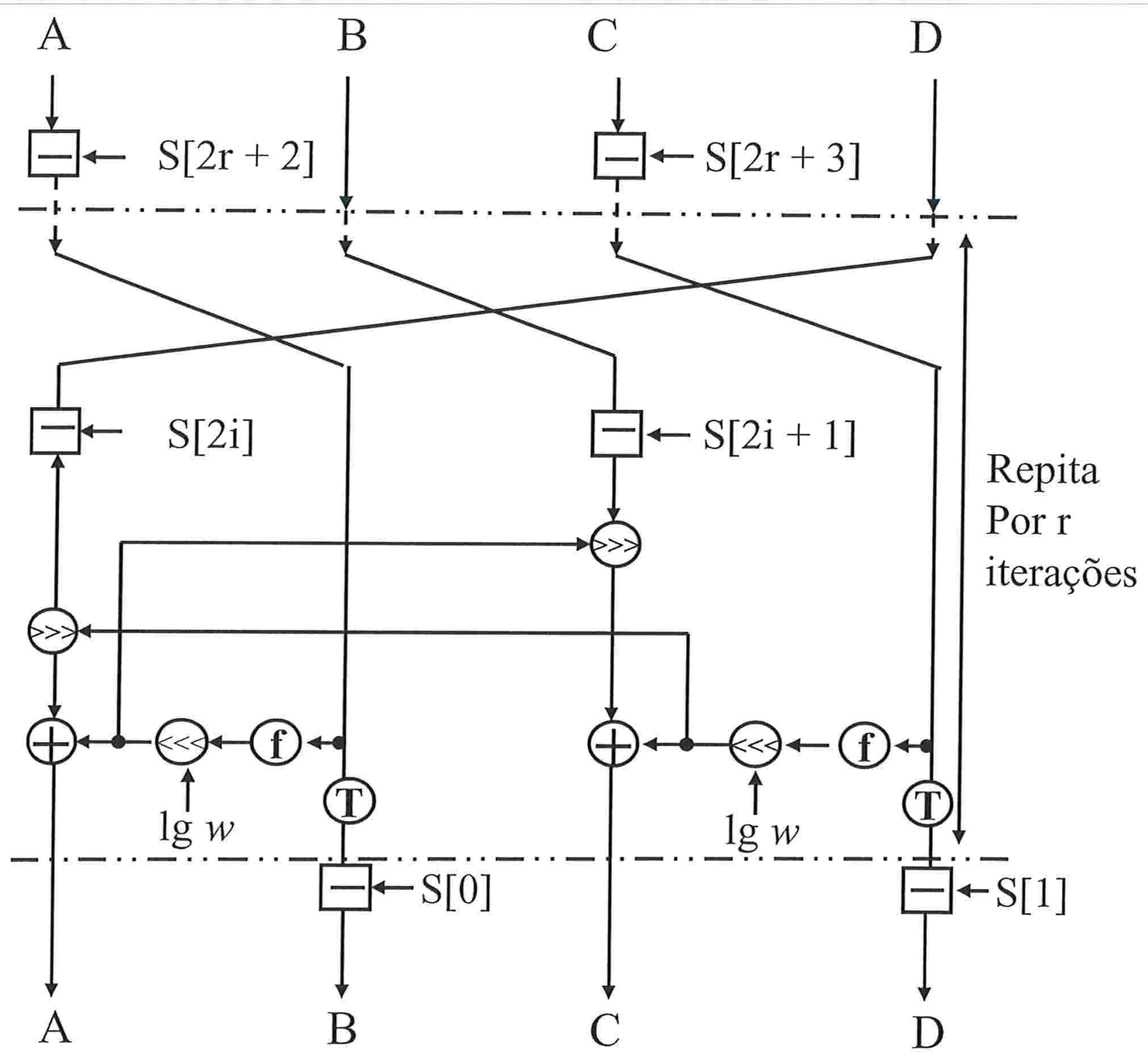

Figura 8.4: Decriptografia com o RC6T-w/r/b. Onde $f(x)=x(2 x+1)$ e $T$ função de troca 


\subsection{Propriedades da função de troca $T$}

A partir desta seção, supomos que, dada uma seqüência de bits $X$ :

- $\operatorname{Imp}(X)$ é o evento "número de bits iguais a 1 em $X$ é ímpar",

- $\operatorname{Par}(X)$ é o evento "número de bits iguais a 1 em $X$ é par" e

- $\operatorname{Sim}(X)$ é o evento " $X$ simétrica.

Definição 8.2.1. Sejam $X$ e $Y$ seqüências de 32 bits. Dizemos que $X$ causa $Y$ pela função $T$ com probabilidade $p$ se por uma fração $p$ de todos os pares cujas diferenças são iguais a $X$, o valor da diferença dos pares após a aplicação de $T$ é $Y$. Indicamos isto por $X \rightarrow Y$, se $p>0$, Caso contrário $X \nrightarrow Y$, se $p=0$.

Definição 8.2.2. Sejam $X_{1}, X_{2}, Y_{1}$ e $Y_{2}$ seqüências de 32 bits tais que $Y_{1}=T\left(X_{1}\right)$ e $Y_{2}=T\left(X_{2}\right)$. Definimos:

$$
\begin{gathered}
\delta_{x}=X_{2}-X_{1}, \\
\delta_{y}=Y_{2}-Y_{1} .
\end{gathered}
$$

Lema 8.2.1. Dadas seqüências como na definição 8.2.2 e $\delta_{x}=2^{i}, 0 \leq i \leq 31$. Então $\delta_{x}=\delta_{y}$ se, e somente se, $\operatorname{Par}\left(X_{1}\right) \wedge \operatorname{Par}\left(X_{2}\right)$.

Demonstração. $(\Rightarrow)$ Por contradição:

Temos três casos:

Caso 1 Vamos supor $\operatorname{Imp}\left(X_{1}\right) \wedge \operatorname{Par}\left(X_{2}\right)$. Temos

$$
\delta_{x}=\delta_{y}
$$

e

$$
X_{2}-X_{1}=Y_{2}-Y_{1}
$$

como $\operatorname{Par}\left(X_{2}\right)$ podemos cancelar $X_{2} \operatorname{com} Y_{2}$, temos então

$$
X_{1}=Y_{1}
$$

e

$$
\left.\left.\left(\left(X_{1}\right)_{E},\left(X_{1}\right)_{D}\right)\right)=\left(\left(X_{1}\right)_{D},\left(X_{1}\right)_{E}\right)\right)
$$

logo, $X_{1}$ é simétrica. (Absurdo!)

Caso 2 Vamos supor $\operatorname{Par}\left(X_{1}\right) \wedge \operatorname{Imp}\left(X_{2}\right)$. Análogo ao caso 1

Caso 3 Vamos supor $\operatorname{Imp}\left(X_{1}\right) \wedge \operatorname{Imp}\left(X_{2}\right)$. Vamos dividir em dois casos:

Para $0 \leq i \leq 15$

Como $\delta_{x}=\delta_{y}=2^{i}$ temos 


$$
\left.\left.\delta_{x}=\left(\left(X_{2}\right)_{E},\left(X_{2}\right)_{D}\right)\right)-\left(\left(X_{1}\right)_{E},\left(X_{1}\right)_{D}\right)\right)=2^{i}
$$

e

$$
\left(\left(X_{2}\right)_{E}-\left(X_{1}\right)_{E},\left(X_{2}\right)_{D}-\left(X_{1}\right)_{D}\right)=2^{i}
$$

então

$$
\begin{gathered}
\left(X_{2}\right)_{D}-\left(X_{1}\right)_{D}=2^{i} \bmod \left(2^{16}\right) \\
\left(X_{2}\right)_{E}-\left(X_{1}\right)_{E}-x=0 \bmod \left(2^{16}\right) \\
\left(X_{2}\right)_{E}-\left(X_{1}\right)_{E}=x \bmod \left(2^{16}\right)
\end{gathered}
$$

onde $x$ é o eventual empréstimo da subtração da seqüência de bits menos significativos,isto é, $x=1$ ou $x=0 \mathrm{e}$

$$
\begin{gathered}
\left(X_{2}\right)_{E}-\left(X_{1}\right)_{E}=0 \bmod \left(2^{16}\right) \text { ou } \\
\left(X_{2}\right)_{E}-\left(X_{1}\right)_{E}=1 \bmod \left(2^{16}\right)
\end{gathered}
$$

De

$$
\left.\left.\delta_{y}=\left(\left(X_{2}\right)_{D},\left(X_{2}\right)_{E}\right)\right)-\left(\left(X_{1}\right)_{D},\left(X_{1}\right)_{E}\right)\right)=2^{i}
$$

e

$$
\begin{gathered}
\left(\left(X_{2}\right)_{D}-\left(X_{1}\right)_{D},\left(X_{2}\right)_{E}-\left(X_{1}\right)_{E}\right)=2^{i} \\
\left(X_{2}\right)_{E}-\left(X_{1}\right)_{E}=2^{i} \bmod \left(2^{16}\right)
\end{gathered}
$$

Das equações $8.1,8.2$ e 8.3 temos que $0=2^{i} \bmod \left(2^{16}\right)$ ou $1=2^{i} \bmod \left(2^{16}\right)($ Absurdo!) Para $16 \leq i \leq 31$ : Com argumentação análoga ao caso anterior também se chega a um absurdo.

$(\Leftarrow)$ Temos que $X_{1}=Y_{1}$ e $X_{2}=Y_{2} \operatorname{logo} \delta_{x}=\delta_{y}$.

Lema 8.2.2. Dadas seqüências como na definição 8.2.2, tais que $X_{1}$ é escolhido aleatoriamente de uma distribuição uniforme e $\delta_{x}=\delta_{y}=2^{i}$. Então a probabilidade $p$ de $\delta_{x} \rightarrow \delta_{y}$ é $p \leq 1 / 4$

Demonstração. Do lema 8.2.1 temos que $\delta_{x}=\delta_{y}=2^{i}$ se, e somente se, $\operatorname{par}\left(X_{1}\right) \wedge \operatorname{par}\left(X_{2}\right)$. Então esta característica vale somente se ocorrerem os seguintes eventos: 

A: $\operatorname{Par}\left(X_{1}\right)$
B: $\operatorname{Par}\left(X_{2}\right), X_{2}=X_{1}+2^{i}$.

Então temos que

$$
p=P[A \cap B]=P[B \mid A] \times P[A]
$$

Como $X_{1}$ é escolhido aleatoriamente de uma distribuição uniforme, $P(A)=1 / 2$.

$$
P[A]=1 / 2 .
$$

A probabilidade $P[B \mid A]$ vai depender da posição de $i$. Vamos dividir $X_{1}$ em duas seqüências, em relação a posição de $i$ : uma à esquerda, $\left(X_{1}\right)_{E}$, começando na posição $i$ e de comprimento $32-i$, e outra, à direita, $\left(X_{1}\right)_{D}$, de comprimento $i$. Como $\operatorname{Par}\left(X_{1}\right)$ as duas metades tem a mesma paridade quanto ao número de bits, isto é, $\operatorname{Par}\left(\left(X_{1}\right)_{E}\right) \wedge \operatorname{Par}\left(\left(X_{1}\right)_{D}\right)$ ou $\operatorname{Impar}\left(\left(X_{1}\right)_{E}\right) \wedge \operatorname{Impar}\left(X_{D}\right)$. A adição de $2^{i}$ somente afetará $\left(X_{1}\right)_{E}$, portanto teremos $\operatorname{Par}\left(X_{2}\right)$ somente se esta adição não alterar a paridade do número de bits de $\left(X_{1}\right)_{E}$. Temos então

$$
\begin{gathered}
\left(X_{2}\right)_{D}=\left(X_{1}\right)_{D} \\
\left(X_{2}\right)_{E}=\left(X_{1}\right)_{E}+1 \bmod \left(2^{32-i}\right)
\end{gathered}
$$

A adição de 1 a sequiência $\left(X_{2}\right)_{E}$ não irá alterar sua paridade, quanto ao número de bits, quando tivermos seqüências de bits 1 terminadas pelo bit 0 , de comprimento par e iniciadas no bit menos significativo, ou para seqüências de bits 1 com comprimento igual ao de $\left(X_{1}\right)_{E}$ e este comprimento for par, pois neste caso o "vai um" não é considerado pois a operação é $\bmod \left(2^{32-i}\right)$. Abaixo alguns exemplos destas seqüências:

$$
\ldots 01, \ldots 0111, \ldots 011111, \ldots, \text { ou } \underbrace{111 \ldots 1111}_{\text {comprimento par }}
$$

A probabilidade de um bit qualquer da seqüência $\mathrm{X}$ ser igual a 1 ou 0 , dado $\operatorname{Par}(X)$ é

$$
P[X[j]=1 \text { ou } 0 \mid \operatorname{Par}(X)]=\frac{\frac{2^{n-2}}{2^{n}}}{P[\operatorname{Par}(X)]}=\frac{1 / 4}{1 / 2}=1 / 2, \quad 0 \leq j \leq 31 .
$$

Para $0 \leq i \leq 31$, temos

$$
P[B \mid A]= \begin{cases}\sum_{k=1}^{\left\lfloor\frac{32-i}{2}\right\rfloor}\left(\frac{1}{2^{2 k}}\right) & \text { se } i \text { é ímpar e } i \neq 31 ; \\ \sum_{k=1}^{\frac{32-i}{2}}\left(\frac{1}{2^{2 k}}\right)+\frac{1}{2^{32-i}} & \text { se } i \text { é par; } \\ 0 & \text { se } i=31, \text { não temos seqüências de comprimento par. }\end{cases}
$$

Vamos calcular para $i$ ímpar

$$
\sum_{k=1}^{\left\lfloor\frac{32-i}{2}\right\rfloor}\left(\frac{1}{2^{2 k}}\right)=
$$




$$
\begin{gathered}
=\frac{1}{4} \times \frac{1-\left(\frac{1}{4}\right)^{\left\lfloor\frac{32-i}{2}\right\rfloor}}{1-\frac{1}{4}} \\
=\frac{1}{3} \times\left(1-\left(\frac{1}{4}\right)^{\left\lfloor\frac{32-i}{2}\right\rfloor}\right)<\frac{1}{3} .
\end{gathered}
$$

Então para as seqüências com $i$ ímpar temos

$$
P[B \mid A]<\frac{1}{3} .
$$

Agora vamos calcular para $i$ par

$$
\begin{gathered}
\sum_{k=1}^{\frac{32-i}{2}}\left(\frac{1}{2^{2 k}}\right)+\frac{1}{2^{32-i}}= \\
=\frac{1}{4} \times \frac{1-\left(\frac{1}{4}\right)^{\frac{32-i}{2}}}{1-\frac{1}{4}}+\left(\frac{1}{4}\right)^{\frac{32-i}{2}} \\
=\frac{1}{3} \times\left(1-\left(\frac{1}{4}\right)^{\frac{32-i}{2}}\right)+\left(\frac{1}{4}\right)^{\frac{32-i}{2}} . \\
=\frac{1}{3}+\frac{2}{3} \times\left(\frac{1}{4}\right)^{\frac{32-i}{2}} .
\end{gathered}
$$

A expressão é crescente em função de $i$ e atinge seu máximo para $i=30$. Então

$$
\begin{gathered}
\operatorname{Max}(P[B \mid A])=\frac{1}{3}+\frac{2}{3} \times \frac{1}{4}=\frac{1}{2} e \\
P[B \mid A] \leq \frac{1}{2} .
\end{gathered}
$$

De $8.4,8.5$ e 8.6 podemos calcular

$$
p=P[A \cap B]=P[B \mid A] \times P[A] \leq \frac{1}{2} \times \frac{1}{2} \leq \frac{1}{4}
$$




\section{Capítulo 9}

\section{Análise do Algoritmo RC6 modificado}

Neste capítulo iremos analisar os efeitos da introdução da função de troca nas características e diferenciais apresentados na seção 7.6. Todas as características apresentadas são as chamadas características estáticas.

\subsection{Características e Diferenciais Iterativos para o RC6T}

Segundo a análise dos autores a melhor forma de criptanálise diferencial é a utilização de diferenciais construídos a partir de características estáticas. Características estáticas são da forma $\delta_{x}=\delta_{y}$ e as utilizadas são as que têm peso de Hamming igual a um, isto é, $\delta_{x}=\delta_{y}=2^{i}$. Vamos indicar como $\Delta_{T}$ a probabilidade da característica $\delta_{x}=\delta_{y}=2^{i}$ de uma iteração da função de troca.

A probabilidade da característica iterativa genérica de seis iterações apresentada na tabela 7.2 é dada por

$$
\rho^{6} \times\left(q_{t} \times p_{s} \times p_{v} \times p_{u} \times q_{u-5} \times q_{u-10}\right) .
$$

Com a introdução da função de troca $T$ teremos

$$
\Delta_{T}^{6} \times \rho^{6} \times\left(q_{t} \times p_{s} \times p_{v} \times p_{u} \times q_{u-5} \times q_{u-10}\right) .
$$

A probabilidade do diferencial iterativo de seis iterações fixando-se $t$ e $u$ é dada por

$$
\begin{aligned}
& \rho^{6} \times q_{11} \times\left(\sum_{i=0}^{26} p_{i}\right)^{2} \times p_{26} \times q_{21} \times q_{16} \\
\approx & 2^{-30} \times 2^{-23} \times\left(2^{-4}\right)^{2} \times 2^{-5} \times 2^{-10} \times 2^{-15} \\
= & 2^{-91} .
\end{aligned}
$$

Com a introdução da função de troca $T$ e utilizando o resultado do lema 8.2.2, onde $\Delta_{T} \leq 1 / 4$, podemos calcular o valor do diferencial iterativo de seis iterações para o RC6T.

$$
\begin{aligned}
& \Delta_{T}^{4} \times \rho^{6} \times q_{11} \times\left(\sum_{i=0}^{26}\left(\Delta_{T} \times p_{i}\right)\right)^{2} \times p_{26} \times q_{21} \times q_{16} \\
\approx & 2^{-8} \times 2^{-30} \times 2^{-23} \times\left(2^{-2} 2^{-4}\right)^{2} \times 2^{-5} \times 2^{-10} \times 2^{-15} \\
= & 2^{-103} .
\end{aligned}
$$


De maneira análoga, baseados em características estáticas, são construídos os outros diferenciais, dai devemos multiplicar os resultados da tabela 7.5 por $\Delta_{T}^{r}$, onde $r$ é o número de iterações, para obtermos os valores apresentados na tabela 9.1 com os resultados para o RC6T.

\begin{tabular}{||c||c|c|c|c|c||}
\hline \multicolumn{1}{||c||}{} & \multicolumn{5}{c||}{ Número de iterações } \\
\hline $\begin{array}{c}\text { Variante } \\
\text { RC6 } \\
\text { Característica Iterativa }\end{array}$ & $2^{109}$ & $2^{175}$ & $2^{246}$ & $2^{319}$ & $2^{385}$ \\
\hline $\begin{array}{c}\text { RC6 } \\
\text { Diferencial Iterativo }\end{array}$ & $2^{107}$ & $2^{171}$ & $2^{242}$ & $2^{313}$ & $2^{377}$ \\
\hline $\begin{array}{c}\text { RC6 } \\
\text { Diferenciais } \\
\text { Ajustados }\end{array}$ & $2^{72}$ & $2^{141}$ & $2^{222}$ & $2^{278}$ & $2^{347}$ \\
$E_{6}^{\prime}$ & $B_{6} \mid E_{4}$ & $\begin{array}{c}B_{6} \mid I_{6} \\
\mid E_{2}\end{array}$ & $\begin{array}{c}B_{6} \mid I_{6} \\
\mid E_{6}\end{array}$ & $\begin{array}{c}B_{6} \mid I_{6} \\
\left|I_{6}\right| E_{4}\end{array}$ \\
\hline
\end{tabular}

Tabela 9.1: Estimativa de textos legíveis para atacar o RC6T [3]

Observando a tabela 9.1 poderíamos afirmar que o RC6T de 12 iterações é seguro contra criptanálise diferencial, pois o número de textos legíveis é superior a $2^{128}$, que é número máximo de textos legíveis possíveis. Para utilizarmos esta versão seria necessário analisarmos a resistência do RC6T contra criptanálise linear. 


\section{Capítulo 10}

\section{Implementação}

A implementação do protocolo TLS foi dividida em duas fases. Na primeira, implementamos o algoritmo RC6 modificado e o incluímos na biblioteca Cryptix versão 3.2, que é uma implementação aberta da especificação Java Cryptography Extensions(JCE) versão 1.1 da Sun disponibilizada pela organização Cryptix. Na segunda fase, implementamos o TLS através da alteração de uma implementação aberta do TLS 1.0 e SSL 3.0 chamada PureTLS versão 0.9b2 disponibilizada pela empresa Claymore Systems. O PureTLS utiliza os algoritmos criptográficos da biblioteca Cryptix versão 3.2.

\subsection{Ambiente de desenvolvimento}

A linguagem Java foi escolhida para a implementação e abaixo temos os componentes do ambiente utilizado:

Sistema Operacional Windows NT 4.0 e Windows 2000;

Java Development Kit JDK 1.2.2

Equipamentos Desktop Pentium III 1Ghz com 256Mb de RAM e HD de 20 GB e notebook Pentium III $450 \mathrm{Mhz}$ com $256 \mathrm{Mb}$ de RAM e HD de $15 \mathrm{~Gb}$.

Bibliotecas Criptográficas Cryptix versão 3.2

\subsection{Algoritmo RC6 modificado}

A diferença entre o RC6 e o RC6T é a introdução de duas funções de troca nas duas metades do bloco iterado do algoritmo, como pode ser observado nas figuras 6.3 e 8.2. Abaixo mostramos a implementação da função de troca que foi implementada como sugerida em [13]. Os passos são os seguintes:

- Construção de uma tabela de paridade,tabpar, de 256 posições, tal que:

$$
\text { tabpar }[i]= \begin{cases}0, & \text { se o número de bits iguais a } 1 \text { em } i \text { é par } \\ 1, & \text { caso contrário. }\end{cases}
$$


A construção desta tabela é simples e rápida, a seguir mostramos a implementação da função de construção em linguagem Java:

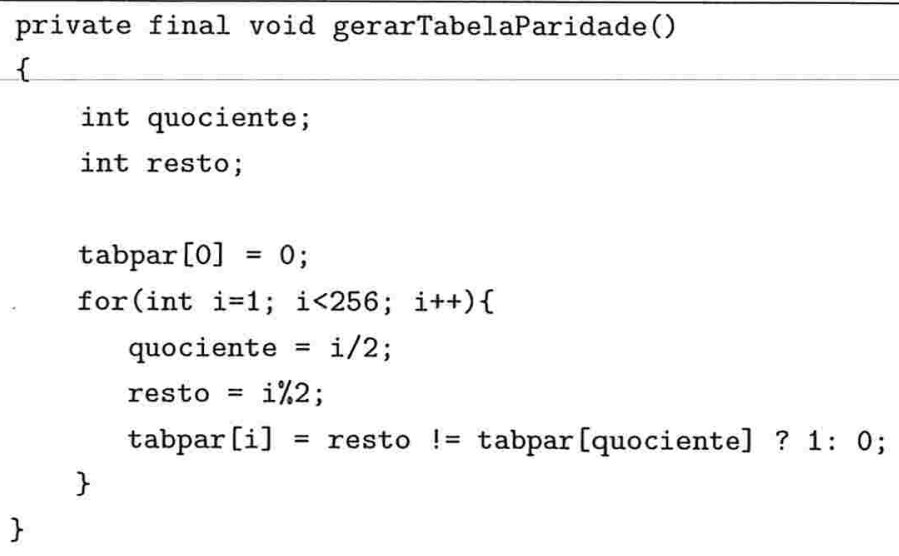

- Agora com a tabela construída podemos efetuar a troca como no trecho de código abaixo:

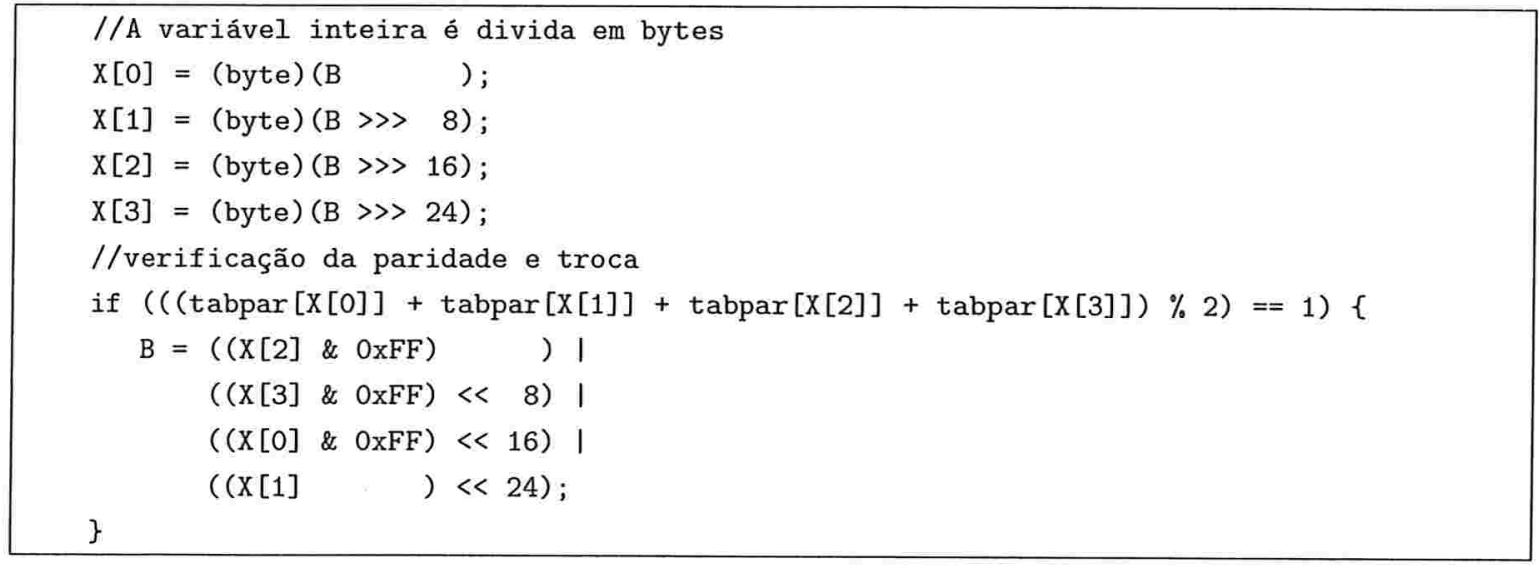

A tabela de paridade é construída por um método que configura todos parâmetros do algoritmo antes do início da criptografia ou decriptografia. Medidas feitas utilizando-se os algoritmos RC6T e RC6 dentro do protocolo TLS mostraram tempo médio $7 \%$ maior quando utilizamos o RC6T.

\subsection{Protocolo TLS 1.0}

A distribuição PureTLS do protocolo TLS 1.0 que foi utilizada tem as seguintes características:

Protocolos Transport Layer Security (TLS) 1.0 e Secure Sockets Layer (SSL) 3.0;

Certificados $X .509 v 3$ com chaves DSS e RSA;

Assinatura Digital DSS com SHA e RSA com MD5; 
Criptografia Assimétrica Diffie-Hellman e RSA;

Criptografia Simétrica DES, 3DES e RC4;

Conjunto de algoritmos(CipherSuites) São implementados os seguintes:

- TLS_DHE_DSS_WITH_DES_CBC_SHA,

- TLS_DHE_DSS_WITH_3DES_EDE_CBC_SHA,

- TLS_RSA_WITH_DES_CBC_SHA,

- TLS_RSA_WITH_3DES_EDE_CBC_SHA,

- TLS_RSA_WITH_RC4_128_MD5, TLS_RSA_WITH_RC4_128_SHA,

- TLS_RSA_EXPORT_WITH_RC4_40_MD5,

- TLS_RSA_EXPORT_WITH_RC2_CBC_40_MD5,

- TLS_RSA_EXPORT_WITH_DES40_CBC_SHA.

\subsubsection{Alterações}

Primeiro os algoritmos RC6 e RC6T foram introduzidos na biblioteca Cryptix. Eles foram implementados por herança da classe abstrata Cipher e implementando a interface SymmetricCipher. Deste modo a implementação do TLS continua utilizando de maneira transparente a classe Cipher.

As alterações na implementação do TLS foram a introdução de dois novos conjuntos de algoritmos(Cipher Suites) e o tratamento para algoritmos criptográficos com blocos de tamanho de 128 bits, pois a implementação utilizada só tratava algoritmos com blocos de tamanho de 64 bits. Os novos conjuntos de algoritmos além do RC6 e RC6T no modo CBC utilizam parâmetros Diffie-Hellman temporários assinados por certificado DSS para troca de chaves e o algoritmo SHA para autenticação das mensagens. Na tabela 10.1 temos um resumo das classes alteradas.

\subsubsection{Utilização}

A partir dos fontes alterados foram geradas as seguintes bibliotecas armazenadas no formato Java Archive(JAR): cryptix32.jar e tls2002.jar. Adicionalmente, também necessitamos da biblioteca cryptix-asn1.jar que implementa o padrão ASN.1. Para utilização do TLS elas devem ser incluídas na variável de ambiente CLASSPATH e então seguir os seguintes passos:

Instalar Cryptix Executar o comando java cryptix.provider.Install. Este comando irá alterar o arquivo java.security.

Certificados Ter disponível arquivos com certificados para as aplicações cliente e servidor.

Chaves Ter disponível arquivos com chaves necessárias ao protocolo.

Outros arquivos Para não ser necessário o cálculo de chaves temporárias durante a negociação do protocolo, é possível carregar chaves previamente calculadas de um arquivo. 


\begin{tabular}{|l|l|l|}
\hline Classe & Descrição & Alteração \\
\hline SSLCipherState & $\begin{array}{l}\text { Gera parâmetros crip- } \\
\text { tográficos para uma } \\
\text { conexão. }\end{array}$ & $\begin{array}{l}\text { Alteração para atender algoritmos com } \\
\text { blocos de tamanho 128 bits. }\end{array}$ \\
\hline SSLCipherSuite & $\begin{array}{l}\text { Definição dos cipher } \\
\text { suites e algoritmos } \\
\text { associados. }\end{array}$ & $\begin{array}{l}\text { Incluídos cipher suites com o RC6 e } \\
\text { RC6T, classe e construtor foram alterados } \\
\text { com um campo booleano para algoritmos } \\
\text { com blocos de 128 bits. }\end{array}$ \\
\hline SSLRecord & $\begin{array}{l}\text { Implementa a camada } \\
\text { Record. }\end{array}$ & $\begin{array}{l}\text { Inclusão de pad com tamanho adequado } \\
\text { para algoritmos de 128 bits. }\end{array}$ \\
\hline SSLServerKeyExchange & $\begin{array}{l}\text { Trata a mensagem } \\
\text { ServerKeyExchange. }\end{array}$ & $\begin{array}{l}\text { Introduzido um rápido teste de primali- } \\
\text { dade com 93\% de certeza, para evitar o } \\
\text { ataque por uso de algoritmos diferentes na } \\
\text { troca de chaves. }\end{array}$ \\
\hline SSLPolicyInt & $\begin{array}{l}\text { Tem a definição da } \\
\text { política de segurança } \\
\text { desejada. }\end{array}$ & $\begin{array}{l}\text { Inclusão } \\
\text { TLS_DHE_DSS_WITH_RC6_CBC_SHA e } \\
\text { TLS_DHE_DSS_WITH_RC6T_CBC_SHA. }\end{array}$ \\
\hline
\end{tabular}

Tabela 10.1: Alterações na implementação do protocolo TLS 1.0

Agora, vamos ver a configuração das classes necessárias para implementarmos uma aplicação utilizando o TLS ${ }^{1}$ :

Classe SSLContext Esta classe mantém todos estados relevantes para uma sessão e conexão.

Classe SSLPolicyInt Nesta classe esta definida a política de segurança desejada. Temos, por exemplo, o conjunto de algoritmos cipher suite, se o cliente deve ser autenticado, se o protocolo a ser negociado é o TLS 1.0 ou o SSL 3.0, o tempo de duração de uma sessão etc.

Classe SSLSocket É implementada por herança da classe Socket. Ela cria uma conexão com um servidor especificado por um endereço e porta, utilizando o protocolo handshake implementado pela classe SSLHandshake.

Classe SSLServerSocket É implementada por herança da classe ServerSocket. Ela cria a porta especificada para atender solicitações de conexão, e o método accept() cria conexões para atender as solicitações criando um novo SSLSocket utilizando o protocolo handshake implementado pela classe SSLHandshake.

Na figura 10.1 temos exemplos de utilização das classes do TLS 1.0 por uma aplicação cliente.

\footnotetext{
${ }^{1}$ Os detalhes das classes e métodos aqui descritos estão na documentação anexa as bibliotecas.
} 
//Criação da classe que conterá o contexto da sessão e conexão SSLContext ctx=new SSLContext();

//Criação da classe onde será definida a política de segurança SSLPolicyInt policy=new SSLPolicyInt();

//Definição da lista de algoritmos que podem participar de uma $/ /$ negociação do protocolo handshake policy.setCipherSuites (cipherSuites);

//Definição sobre certificados

policy.acceptUnverifiableCertificates (acceptunverified);

//Definição sobre verificação de certificados policy.checkCertificateDates (checkDates);

//Definição sobre protocolo que será negociado. policy.negotiateTLS (negotiateTLS);

//Uma vez configurada a política ela faz parte do contexto. ctx.setPolicy (policy);

//outras definições do contexto.

ctx.loadRootCertificates (rootfile);

ctx.loadEAYKeyFile(keyfile,password);

//Agora já podemos instanciar um conexão

SSLSocket $\mathrm{s}=$ new SSLSocket (ctx, host, port);

//Após a conexão posso verificar o cipher suite escolhido int $\mathrm{cs}=\mathrm{s}$.getCipherSuite();

//E também a cadeia de certificados

Vector $\mathrm{cc}=$ s.getCertificateChain();

//A escrita e leitura da conexão utiliza os mesmos métodos

//utilizados com a classe Socket $\cdots$

Figura 10.1: Exemplos de utilização das Classes do TLS 1.0 


\subsection{Aplicação distribuída para testes}

Utilizamos uma aplicação simulando um cliente web e outra simulando um servidor web. Estas aplicação são parametrizáveis, onde podemos escolher os parâmetros da política de segurança, os conjuntos de algoritmos e endereço e porta para conexão.

A aplicação servidor contida no arquivo SSLServer.java cria uma porta para "escutar" solicitações de aplicações clientes e utiliza um looping para aceitar solicitações. A cada solicitação aceita, responde com mensagens com informação sobre os parâmetros da conexão. A aplicação cliente contida no arquivo SSLClient.java faz solicitações ao servidor e imprime as mensagens enviadas pelo servidor. Foram executados testes com três aplicações clientes fazendo solicitações simultâneas, com conjunto de algoritmos diferentes, ao servidor e não foram verificados problemas com nossa implementação.

Também realizamos testes básicos de desempenho dos algoritmos RC6 e RC6T com 20 iterações e o RC6T com 12 iterações, utilizando o método System.currentTimeMillis(). Estes testes foram realizados com os algoritmos sendo chamados pelo TLS para mensagens de bytes seqüenciais de $32 K b$. O RC6T teve tempo médio superior em $11 \%$ com relação ao RC6, enquanto o RC6 teve tempo médio superior em 40\% em relação ao RC6T com 12 iterações, ver figura 10.2. 


\begin{tabular}{|c|c|c|c|}
\hline Testes & RC6 & RC6T & RC6T-12 \\
\hline 1 & 60 & 80 & 40 \\
\hline 2 & 50 & 70 & 50 \\
\hline 3 & 50 & 60 & 30 \\
\hline 4 & 80 & 50 & 30 \\
\hline 5 & 30 & 70 & 30 \\
\hline 6 & 70 & 80 & 40 \\
\hline 7 & 60 & 70 & 50 \\
\hline 8 & 70 & 50 & 40 \\
\hline 9 & 40 & 50 & 50 \\
\hline 10 & 70 & 70 & 40 \\
\hline 11 & 80 & 50 & 70 \\
\hline 12 & 50 & 70 & 30 \\
\hline 13 & 60 & 50 & 40 \\
\hline 14 & 60 & 80 & 30 \\
\hline 15 & 40 & 70 & 50 \\
\hline Média & 58 & 65 & 41 \\
\hline Desvio & 15 & 12 & 11 \\
\hline & & & \\
\hline
\end{tabular}

Figura 10.2: Resultados dos testes com o RC6, RC6T com 20 iterações e RC6T com 12 iterações. Mensagens de $32 \mathrm{~Kb}$ e tempos em milisegundos. 


\section{Capítulo 11}

\section{Conclusão}

Protocolos criptográficos têm um papel fundamental para aplicações distribuídas. Estes protocolos vêem sendo fortalecidos pelo aumento da resistência a manipulação e pelo fortalecimento das primitivas criptográficas utilizadas.

Nesta dissertação seguimos a estratégia de estudarmos protocolos e algoritmos publicados analisando-os quanto aos objetivos de segurança desejados e resistência a ataques conhecidos.

Nos Capítulos três e quatro estudamos a especificação do protocolo TLS 1.0 e concluímos que ele atinge os objetivos propostos de segurança. O único problema foi a omissão de uma advertência quanto ao ataque mostrado em [14]. Este ataque é dependente da implementação, mas seria importante uma advertência quanto a essa possibilidade de ataque.

O RC6 analisado nos capítulos seis e sete, como um dos finalistas do AES, pode ser considerado um algoritmo seguro em relação ao estado da arte. Mas uma alteração visando seu fortalecimento pode trazer conseqüências importantes, como a diminuição do número de iterações e eventuais ganhos em desempenho.

Com o estudo da introdução da função de troca no RC6, nos capítulos oito e nove, demonstramos que esta função mantém suas propriedades básicas mesmo quando a medida de diferença dos pares da característica é a diferença de inteiros, fornecendo uma diminuição da probabilidade da característica menor ou igual a 1/4 por iteração.

A principal contribuição é a disponibilização de uma especificação e uma implementação de um protocolo criptográfico seguro em relação ao estado da arte para utilização em aplicações distribuídas em uma linguagem independente de plataforma. Na verdade este protocolo estende os serviços do protocolo de transporte TCP que é um padrão para a rede Internet e outras redes, e a quantidade aplicações que utilizam este serviço é muito grande.

\subsection{Trabalhos futuros}

O estudo das características para o RC6 foi restrito as características estáticas de peso de Hamming igual a um. O que restringe muito o escopo de características. Seria de grande interesse a avaliação de características estáticas com peso de Hamming diferente de um e características não estáticas para o RC6 e RC6T.

Um outro trabalho interessante seria a utilização de métodos formais para validação de protocolos criptográficos. 


\section{Apêndice A}

\section{Glossário}

ASN.1 Um padrão da ISO/ITU-T para transmissão de dados estruturados em redes.

Assinatura Digital Provê um meio de ligar a identidade de uma entidade à uma mensagem ou informação no formato digital. O processo de assinatura implica na transformação da mensagem com alguma informação secreta, conhecida somente pela entidade, em um conjunto de dados chamado de assinatura. Um esquema de assinatura consiste de dois componentes: Um algoritmo para assinatura e um algoritmo para verificação da assinatura.

Block Cipher Algoritmo de criptografia que tem como entrada blocos de tamanho fixo do texto legível sendo criptografado.

Bulk Cipher Algoritmo de criptografia de chave simétrica utilizado para criptografar grandes quantidades de dados.

Cipher Block Chaining (CBC) CBC é um modo de operação em que os blocos de texto legível a serem criptografados por um block cipher, primeiro passam pela operação orexclusivo com o bloco previamente criptografado, ou quando for o primeiro bloco a ser criptografado, a operação é feita com o vetor de iniciação.

CA Autoridade certificadora responsável por estabelecer e garantir a autenticidade de chaves públicas. Em sistemas baseados em certificados, também esta incluído, ligar chaves públicas a nomes distintos através de certificados assinados, gerenciar números seriais de certificados e a revogação dos mesmos.

Certificate Revocation List ( CRL) Lista assinada de chaves públicas revogadas, cada entrada indica o número de série do certificado associado, a data da revogação e os motivos. A lista é emitida e assinada pelo CA que emitiu os certificados.

Digital Signature Standard (DSS) Padrão para assinatura digital aprovado pelo National Institute of Standards and Technology, definido em NIST FIPS PUB 186, "Digital Signature Standard," published May, 1994 by the U.S. Dept. of Commerce.

Message Authentication Code (MAC) É o resultado do cálculo de uma função oneway hash a partir de uma mensagem e algum dado secreto. A falsificação do resultado 
da operação é impraticável sem o conhecimento do dado secreto. Seu objetivo é verificar se a mensagem foi alterada.

MD5 Função de hash segura que converte uma cadeia de caracteres de tamanho arbitrário para um resumo de comprimento fixo de 16 bytes.

One-way hash function Função que converte uma quantidade arbitrária de dados em um valor de hash de tamanho fixo. É computacionalmente difícil calcular uma função inversa ou encontrar colisões.

RSA Algoritmo de chave pública que pode ser usado para criptografia e assinatura digital.

SHA Abreviação de Secure Hash Algorithm, função de hash definida em FIPS PUB 180-1. Ela produza uma saída de 20 bytes.

Stream cipher Algoritmo de criptografia que converte uma chave em uma seqüência de chaves criptograficamente fortes, que então passam pela operação or-exclusivo com o texto legível.

Vetor de Iniciação Em inglês Initialization Vector (IV). Quando um block cipher é utilizado no modo de operação CBC ele é utilizado na operação or-exclusivo com o primeiro bloco de texto legível a ser criptografado. 


\section{Referências Bibliográficas}

[1] E. Biham and A. Shamir. Differential cryptanalysis of des-like cryptosystems. Journal of Cryptology: the journal of the International Association for Cryptologic Research, 4(1):3-72, 1991.

[2] CCITT. Recommendation x.509: The directory - authentication framework, 1988. Available electronically at http://www.itu.int/itudoc/itu-t/rec/x/x500up/x509.html.

[3] S. Contini, R. Rivest, M. Robshaw, and Y. Yin. The security of the rc6 block cipher, 1998. S. Contini, R.L. Rivest, M.J.B. Robshaw and Y.L. Yin. The Security of the RC6 Block Cipher. v.1.0, 20 de agosto de 1998. Disponível em www.rsa.com/rsalabs/aes/.

[4] J. Daemen and V. Rijmen. Aes proposal: Rijndael. J. Daemen and V. Rijmen. AES Proposal: Rijndael. www.esat.kuleuven.ac.be/ rijmen/rijndael/.

[5] T. Dierks and C. Allen. The tls protocol version 1.0, 1999. T. Dierks and C. Allen, The TLS protocol version 1.0, Request for Comments 2246, Internet Engineering Task Force, Jan. 1999.

[6] Whitfield Diffie and Martin E. Hellman. New directions in cryptography. IEEE Transactions on Information Theory, IT-22(6):644-654, 1976.

[7] H. Dobbertin and o MD. Presented at the rump session of eurocrypt, 1996. H. Dobbertin. Cryptanalysis of MD5 Compress. Presented at the rump session of Eurocrypt '96, May 14, 1996.

[8] H. Krawczyk, M. Bellare, and R. CanettiNetwork Working Group. Rfc2104 rfc.net page 1 of 12 .

[9] X. Lai, J. Massey, and S. Murphy. Markov ciphers and differential cryptanalysis, 1991. X. Lai, J. L. Massey, and S. Murphy, Markov Ciphers and Differential Cryptanalysis, Advances in Cryptology - EUROCRYPT'91, Lecture Notes in Computer Science 547, pp.17-38, Springer-Verlag, 1991.

[10] Alfred Menezes, Paul C. van Oorschot, and Scott A. Vanstone. Handbook of Applied Cryptography. CRC Press, 1996.

[11] NIST. Announcing request for candidate algorithm nominations for the advanced encryption standard (aes, 1997. National Institute of Standards and Technology, Announcing Request for Candidate Algorithm Nominations for the Advanced Encryption Standard (AES), Federal Register, v. 62, n. 117, 12 Sep 1997, pp. 48051-48058. 
[12] R. Rivest, M. Robshaw, R. Sidney, and Y. Yin. The rc6 block cipher, 1998. R. Rivest M. Robshaw, R. Sidney, and Y. Yin, The RC6 block cipher, First Advanced Encryption Standard (AES) Conference, 1998.

[13] R.Terada, P. G. Pinheiro, and K. Koyama. A new version of FEAL, stronger against differential cryptanalysis. TIEICE: IEICE Transactions on Communications/Electronics/Information and Systems, E79-A(1), Janeiro 1996.

[14] Bruce Schneier and David Wagner. Analysis of ssl 3.0 protocol, 1997.

[15] Andreas Sterbenz and Peter Lipp. Performance of the AES candidate algorithms in Java. In NIST, editor, The Third Advanced Encryption Standard Candidate Conference, April 13-14, 2000, New York, NY, USA, pages 161-168, Gaithersburg, MD, USA, 2000. National Institute for Standards and Technology.

[16] Douglas Robert Stinson. Cryptography: Theory and Practice, chapter The Data Encryption Standard, pages 70-104. CRC Press, Boca Raton, 1 edition, 1995.

[17] Routo Terada. Segurança de Dados - Criptografia em redes de computador. Editora Edgard Blücher Ltda, 2000. 